University of Wollongong

Research Online

Faculty of Engineering and Information

Faculty of Engineering and Information

Sciences - Papers: Part B

Sciences

2018

Effect of isochronal annealing on the microstructure, texture and mechanical properties of a cold-rolled high manganese steel

Sudipta Pramanik

University of Wollongong, sp345@uowmail.edu.au

Ahmed A. Saleh

University of Wollongong, asaleh@uow.edu.au

Elena V. Pereloma

University of Wollongong, elenap@uow.edu.au

Azdiar Adil Gazder

University of Wollongong, azdiar@uow.edu.au

Follow this and additional works at: https://ro.uow.edu.au/eispapers1

Part of the Engineering Commons, and the Science and Technology Studies Commons

Research Online is the open access institutional repository for the University of Wollongong. For further information contact the UOW Library: research-pubs@uow.edu.au 


\title{
Effect of isochronal annealing on the microstructure, texture and mechanical properties of a cold-rolled high manganese steel
}

\author{
Abstract \\ A Fe-17Mn-3Al-2Si-1Ni-0.06C wt.\% steel was subjected to cold-rolling to $42 \%$ thickness reduction and \\ isochronally annealed for $300 \mathrm{~s}$ between 500 and $850^{\circ} \mathrm{C}$. The high $\mathrm{Mn}$ steel was characterised via \\ electron back-scattering diffraction, transmission electron microscopy and uniaxial tensile testing. The \\ reversion of deformation-induced $\varepsilon$ and $\alpha^{\prime}$-martensite to austenite $(\gamma)$ was witnessed with the formation \\ of fine twins in reverted/recovered $\gamma$ grains after annealing to $650{ }^{\circ} \mathrm{C}$. The nucleation of new $\gamma$ grains at \\ the boundary of reverted/recovered $\gamma$ grains was also noted. Upon reversion, the $\gamma$ orientations originated \\ from the $\varepsilon$ and $\alpha$ '-martensite orientations by phase transformation via the Shoji-Nishiyama and \\ Kurdjumov-Sachs orientation relationships, respectively. Upon segmenting the $Y$ grains, the recrystallised \\ $Y$ grains were observed to nucleate with orientations similar to those of the reverted/recovered $Y$ grains. \\ Uniaxial tension on a fully recrystallised $\gamma$ microstructure showed that the initial $\gamma$ grain size has a more \\ significant effect on the yield strength than the $\varepsilon$ and $\alpha$-martensite fractions. On the other hand, the initial \\ $\varepsilon$ and $\alpha^{\prime}$-martensite fractions affect the total elongation.

\section{Disciplines} \\ Engineering | Science and Technology Studies

\section{Publication Details} \\ Pramanik, S., Saleh, A. A., Pereloma, E. V. \& Gazder, A. A. (2018). Effect of isochronal annealing on the \\ microstructure, texture and mechanical properties of a cold-rolled high manganese steel. Materials \\ Characterization, 144 66-76.
}




\title{
Effect of isochronal annealing on the microstructure, texture and mechanical properties of a
} cold-rolled high manganese steel

\author{
Sudipta Pramanik ${ }^{1}$, Ahmed A. Saleh ${ }^{1}$, Elena V. Pereloma ${ }^{1,2}$, Azdiar A. Gazder ${ }^{2}$ \\ 1School of Mechanical, Materials, Mechatronic and Biomedical Engineering, University of Wollongong, \\ New South Wales 2522, Australia \\ Electron Microscopy Centre, AIIM, Innovation Campus, Squires Way, Wollongong, New South Wales \\ 2500, Australia
}

\begin{abstract}
An Fe-17Mn-3Al-2Si-1Ni-0.06C wt.\% steel was subjected to cold-rolling to $42 \%$ thickness reduction and isochronally annealed for $300 \mathrm{~s}$ between 500 and $850{ }^{\circ} \mathrm{C}$. The high $\mathrm{Mn}$ steel was characterised via electron back-scattering diffraction, transmission electron microscopy and uniaxial tensile testing. The reversion of deformation-induced $\varepsilon$ and $\alpha^{\prime}$-martensite to austenite $(\gamma)$ was witnessed with the formation of fine twins in reverted/recovered $\gamma$ grains after annealing to $650{ }^{\circ} \mathrm{C}$. The nucleation of new $\gamma$ grains at the boundary of reverted/recovered $\gamma$ grains was also noted. Upon reversion, the $\gamma$ orientations originated from the $\varepsilon$ and $\alpha^{\prime}$-martensite orientations by phase transformation via the Shoji-Nishiyama and Kurdjumov-Sachs orientation relationships, respectively. Upon segmenting the $\gamma$ grains, the recrystallised $\gamma$ grains were observed to nucleate with orientations similar to those of the reverted/recovered $\gamma$ grains. Uniaxial tension on a fully recrystallised $\gamma$ microstructure showed that the initial $\gamma$ grain size has a more significant effect on the yield strength than the $\varepsilon$ and $\alpha^{\prime}$-martensite fractions. On the other hand, the initial $\varepsilon$ and $\alpha^{\prime}$-martensite fractions affect the total elongation.
\end{abstract}

Keywords: electron microscopy; hardness; iron alloys; phase transformation; plasticity 


\section{Introduction}

High strength steels containing 15-20 wt.\% manganese possess low stacking fault energies (SFE) that enable the metastable face-centred cubic (fcc) austenite $(\gamma)$ phase to accommodate deformation by a combination of perfect and partial slip, twinning and phase transformation to hexagonal closed packed (hcp) $\varepsilon$-martensite and/or body-centered cubic (bcc) $\alpha^{\prime}$-martensite [1-3]. Generally, steels with SFE less than $\sim 21 \mathrm{~mJ} / \mathrm{m}^{2}$ result in the formation of $\varepsilon$ and $\alpha^{\prime}$-martensite whereas SFE between $\sim 12-21$ $\mathrm{mJ} / \mathrm{m}^{2}$ result in the formation of twins and $\varepsilon$ and $\alpha^{\prime}$-martensite. The pathways to phase transformation are: (i) $\gamma$ directly transforming to $\alpha^{\prime}$-martensite and (ii) $\gamma$ transforming to $\alpha^{\prime}$-martensite via prior transformation to $\varepsilon$-martensite $[1,4]$.

Upon annealing, the deformation-induced $\varepsilon$ and $\alpha^{\prime}$-martensite revert to $\gamma$; with the latter phase undergoing subsequent recrystallisation [1, 3, 5-7]. The reverse transformation of $\varepsilon$-martensite occurs between 100 and $250{ }^{\circ} \mathrm{C}$ while the reversion of $\alpha^{\prime}$-martensite occurs between 500 and $700{ }^{\circ} \mathrm{C}$ for the high Mn steel used in the present investigation [8]. Lü et al. [3] reported the formation of highly dislocated, reverted $\gamma$ when an Fe-21.6Mn-0.38C steel (all compositions in wt. \% from here on) coldrolled to $50 \%$ thickness reduction was subsequently annealed at $630{ }^{\circ} \mathrm{C}$. Kowalska et al. [7] observed fine twins in reverted $\gamma$ along with remnant deformation-induced $\alpha^{\prime}$-martensite when an Fe-26Mn$3 \mathrm{Al}-3 \mathrm{Si}$ steel cold-rolled to $57 \%$ thickness reduction was annealed at $500{ }^{\circ} \mathrm{C}$. In that study, the onset of $\gamma$ recrystallisation was noted at $650^{\circ} \mathrm{C}$.

Upon annealing, the orientations of reverted $\gamma$ are derived from the orientations of their deformationinduced $\varepsilon$ and $\alpha^{\prime}$-martensite counterparts via the Shoji-Nishiyama (S-N, $\{111\}_{\gamma}\left\|\{0001\}_{\varepsilon},\langle 110\rangle_{\gamma}\right\|$ $\langle 11 \overline{2} 0\rangle_{\varepsilon}$ [9]) and the Kurdjumov-Sachs (K-S, $\{111\}_{\gamma}\left\|\{110\}_{\alpha^{\prime}},\langle 110\rangle_{\gamma}\right\|\langle 111\rangle_{\alpha^{\prime}}$ [10]) orientation relationships, respectively. In this regard, Lü et al. [3] showed the reversion of $\{01 \overline{1} 4\}\langle 1 \overline{2} 12\rangle_{\varepsilon}$ to $\{123\}\langle 412\rangle_{\gamma}$ in an Fe-21.6Mn-0.38C steel cold-rolled to 50\% thickness reduction and annealed at 630 ${ }^{\circ} \mathrm{C}$. Kowalska et al. [7] observed reversion to the Brass $\left(\mathrm{Br}_{\gamma},\{110\}\langle 112\rangle_{\gamma}\right)$, Copper $\left(\mathrm{Cu}_{\gamma},\{112\}\langle 111\rangle_{\gamma}\right)$, Goss $\left(G_{\gamma},\{110\}\langle 001\rangle_{\gamma}\right)$ and $S_{\gamma}\left(\{123\}\langle 634\rangle_{\gamma}\right)$ orientations from the $\{h k i l\}_{\varepsilon}$-fibre orientations and $\{001\}\langle 110\rangle_{\alpha^{\prime}},(112)[1 \overline{1} 0]_{\alpha^{\prime}}$ when an Fe-26Mn-3Al-3Si steel cold-rolled to $57 \%$ thickness reduction was subjected to isochronal annealing at 500,650 and $750{ }^{\circ} \mathrm{C}$.

Annealed high Mn steels are reported to possess ultimate tensile strengths (UTS) and total elongation greater than $1100 \mathrm{MPa}$ and 0.55 , respectively $[11,12]$. A comprehensive collection of literature-based tensile properties of metastable high Mn steels has been presented by the authors in Ref. [13]. High Mn steels processed by cold-rolling and annealing after hot-rolling and solution treatment $[14,15]$ show slightly higher tensile strengths compared to steels processed by hot-rolling and solution treatment only [16-18]; primarily on account of the smaller $\gamma$ grain size in the former case. In addition, multiphase high Mn steels [8] tend to possess higher yield strengths (YS) and UTS of 465 - 1231 MPa and 856 - $1376 \mathrm{MPa}$ compared to their single-phase counterparts (YS = 168-434 MPa, UTS = 698-822 $\mathrm{MPa})[14]$. 
The Fe-17Mn-3Al-2Si-1Ni-0.06C steel of this study was cold-rolled to $66 \%$ thickness reduction and subjected to isochronal annealing. Microstructure characterisation via transmission Kikuchi diffraction (TKD) by Gazder et al. [5, 6] revealed the formation of deformation-induced $\varepsilon$ and $\alpha^{\prime}$ martensite and a trace amount of $\gamma$ upon cold rolling. Upon annealing at $625^{\circ} \mathrm{C}$, the microstructure comprised a predominant fraction of reverted and recrystallised $\gamma$ (with the recrystallised $\gamma$ grains containing stacking faults) along with untransformed $\alpha^{\prime}$-martensite and a trace fraction of $\varepsilon$ martensite. In the case of the same steel cold-rolled to $42 \%$ thickness reduction and subjected to isochronal annealing, an electron back-scattering diffraction (EBSD) study estimated an activation energy of $237.2 \pm 17.3(\mathrm{~kJ} / \mathrm{mol})$ for $\gamma$ grain growth between 700 and $900{ }^{\circ} \mathrm{C}$ annealing; a value that suggests the operation of grain boundary diffusion [19]. In addition, the activation energy of $\gamma$ grain growth in Fe-29Mn-0.06C high Mn steel during isothermal annealing at $1000{ }^{\circ} \mathrm{C}$ was estimated as 208 $\mathrm{kJ} / \mathrm{mol}$ [20]. In this regard, the activation energy for $\gamma$ grain growth for Fe-1.51Mn-0.03Si-0.17C, Fe1.43Mn-0.03Si-0.12C and Fe-0.86Mn-0.03Si-0.11C plain carbon steels is estimated as $\sim 262,271$ and $272 \mathrm{~kJ} / \mathrm{mol}$ respectively [21]; values that are slightly higher than high Mn steel. For C-Mn-V, C-Mn-Ti, $\mathrm{C}-\mathrm{Mn}-\mathrm{Nb}$ based micro-alloyed low carbon steels, the activation energy for $\gamma$ grain growth is reported as 400,437 and $435 \mathrm{~kJ} / \mathrm{mol}$ respectively [22]; values that are almost double those compared to high Mn steels. Digital image correlation during room temperature, uniaxial tension after cold-rolling and isochronal annealing revealed strain localisation accompanying deformation-induced phase transformation all along the parallel gauge length [13].

In this regard, the present study presents an overview of the effect of isochronal annealing on the microstructure, texture and mechanical properties of a $42 \%$ cold-rolled high manganese steel via a combination of EBSD, transmission electron microscopy (TEM) and room temperature uniaxial tensile testing. It details the orientations of deformation-induced $\varepsilon$ and $\alpha^{\prime}$-martensite that lead to particular $\gamma$ orientations upon reversion. Furthermore, this is the first study to segment the $\gamma$ phase into its reverted/recovered and recrystallised fractions in order to catalogue the differences in morphology and micro-texture between them.

\section{Experimental and analytical procedure}

An Fe-17Mn-3Al-2Si-1Ni-0.06C steel was slab cast and reheated at $1100{ }^{\circ} \mathrm{C}$ for $7200 \mathrm{~s}$. The slab was hot-rolled at $1100{ }^{\circ} \mathrm{C}$ to $52.5 \%$ thickness reduction in 4 passes to 516 (length) $\times 60$ (width) $\times \sim 9.8$ (thickness) $\mathrm{mm}^{3}$. The hot-rolled specimens were subsequently cold-rolled to $42 \%$ thickness reduction in 11 passes to 759 (length) $\times 60$ (width) $\times \sim 5.4$ (thickness) $\mathrm{mm}^{3}$.

Dog-bone shaped ASTM-EM8-04 standard subsize tensile samples of 35 (gauge length) $\times 6$ (width) $\times 2$ (thickness) $\mathrm{mm}^{3}$ were wire-cut from the centre of the cold-rolled sheet parallel to the rolling (RD), transverse (TD) and normal (ND) directions, respectively. Similarly, 10 (length, RD) $\times 7$ (width, TD) $\times$ $\sim 5.4$ (thickness, ND) $\mathrm{mm}^{3}$ rectangular samples were wire-cut from the centre of the cold-rolled sheet. The dog-bone and rectangular samples were isochronally annealed at 500,600, 625, 650, 700, 750, 
800 and $850{ }^{\circ} \mathrm{C}$ for $300 \mathrm{~s}$ and immediately water quenched. In this regard, supplementary Fig. S1 shows the schematic diagram for processing and subsequent sample preparation.

The hardness of the cold-rolled and annealed rectangular samples was measured using a Struers EmcoTest Durascan-70 equipped with a Vickers indenter using a $10 \mathrm{kgf}$ load on the ND-RD plane. Ten indents were undertaken on each sample and the average hardness reported along with the standard deviation. The softening fraction $(\mathrm{X})$ was calculated from the hardness values using the equation [23]: $\mathrm{X}=\left(\mathrm{H}_{\mathrm{R}}-\mathrm{H}_{\mathrm{T}}\right) /\left(\mathrm{H}_{\mathrm{R}}-\mathrm{H}_{0}\right)$

where, $H_{R}$ is the hardness after cold-rolling, $H_{T}$ is the hardness after annealing at temperature ' $T$ ' between 500 and $800{ }^{\circ} \mathrm{C}$ and $\mathrm{H}_{0}$ is the hardness after annealing at $850^{\circ} \mathrm{C}$.

The dog-bone samples were subjected to uniaxial tension at room temperature on a $100 \mathrm{kN}$ Instron 1341 universal testing machine operating with an initial crosshead speed of $0.035 \mathrm{~mm} / \mathrm{s}$ at a strain rate of $0.001 \mathrm{~s}^{-1}$.

Electron transparent thin foils for microstructural characterisation via EBSD and transmission electron microscopy (TEM) were prepared by punching $3 \mathrm{~mm}$ diameter discs from the ND-RD plane. The punched discs were ground using 2400 grit abrasive paper to achieve a final thickness of $\sim 60-70$ $\mu \mathrm{m}$ and then twin-jet electropolished at $-25^{\circ} \mathrm{C}$ using a solution of $90 \%$ methanol and $10 \%$ perchloric acid in a Struers Tenupol-5 operating at $30 \mathrm{~V}(\sim 150 \mathrm{~mA})$.

For texture characterisation, the RD-ND plane of the rectangular samples was ground using 2400 grit abrasive paper and electro-polished in a Struers LectroPol-5 operating at $50 \mathrm{~V}$ for $90 \mathrm{~s}$ with a solution of $330 \mathrm{ml}$ methanol, $330 \mathrm{ml}$ butoxyethanol and $40 \mathrm{ml}$ perchloric acid.

EBSD was undertaken on a JEOL JSM-7001F field emission gun-scanning electron microscope operating at $15 \mathrm{kV}$ accelerating voltage, $\sim 6.5 \mathrm{nA}$ probe current. The working distances for electron transparent foils and rectangular samples were 12 and $15 \mathrm{~mm}$, respectively. For microstructure characterisation, a step size of $0.03 \mu \mathrm{m}$ was used for the cold-rolled, 500, 625 and $650{ }^{\circ} \mathrm{C}$ annealed samples. A step size of $0.1 \mu \mathrm{m}$ was used for the $700-850{ }^{\circ} \mathrm{C}$ annealed samples. For bulk texture work, step sizes of $1 \mu \mathrm{m}$ was used for the cold-rolled and 500-650 ${ }^{\circ} \mathrm{C}$ annealed samples, $2 \mu \mathrm{m}$ for the 700 and $750{ }^{\circ} \mathrm{C}$ annealed samples and $2.5 \mu \mathrm{m}$ for the hot-rolled, 800 and $850^{\circ} \mathrm{C}$ annealed samples.

Post-processing of the EBSD maps for microstructure characterisation was undertaken using the Oxford Instruments (OI) Channel-5 software suite. In brief, it involved the removal of wild spikes and cyclic extrapolation of zero solutions up to five neighbours followed by thresholding the band contrast to delineate the unindexed regions. The band contrast map was superimposed on the phase maps such that the red, green, blue and white colours denote the $\gamma, \varepsilon, \alpha^{\prime}$-martensite phases and unindexed regions, respectively. Boundary misorientations of $2^{\circ}-15^{\circ}$ and greater than $15^{\circ}$ comprise low (LAGBs) and high (HAGBs) -angle grain boundaries, respectively. As per the Palumbo-Aust criterion $\left(\Delta \theta \leq 15^{\circ}\right.$ $\Sigma^{-5 / 6}$ ), $\Sigma 3 \gamma$-twin boundaries have a maximum angular deviation of $6.03^{\circ}$ from the ideal misorientation angle-axis of $60^{\circ} /\langle 111\rangle_{\gamma}$ [24]. $\{10 \overline{1} 2\}\langle\overline{1} 011\rangle_{\varepsilon}$ extension twins denoted as $\sim 86^{\circ} /\langle 1 \overline{2} 10\rangle_{\varepsilon}$ are shown 
using a $5^{\circ}$ deviation limit [25]. The orientation distribution functions (ODFs) are plotted using JTex [26] after exporting the orientation data from OI Channel-5.

After hot-rolling, the microstructure consists of coarse $\gamma$ grains containing plate like $\varepsilon$-martensite and lenticular $\alpha^{\prime}$-martensite with the area fractions $68 \%, 12 \%$ and $20 \%$, respectively [27]. The EBSD maps of the 600,625 and $650{ }^{\circ} \mathrm{C}$ annealed samples were segmented into reverted/recovered and recrystallised $\gamma$ grain fractions by modifying the modifying the procedure developed by Gazder et al. $[28,29]$. A threshold based on internal misorientation was first applied to segment $\gamma$ grains into two subsets comprising lower and higher internal misorientations. A sub-grain aspect ratio threshold [29] was applied to the lower internal misorientation subset in order to further segment the recrystallised and recovered grains. The recovered grains were merged with the higher internal misorientation $\gamma$ grains in order to return the reverted/recovered $\gamma$ grain fraction. It follows that the recrystallised $\gamma$ fraction comprises grains with lower internal misorientations and sub-grain aspect ratios.

Conventional TEM was undertaken on $\mathrm{LaB}_{6}$ JEOL JEM-2010 operating at $200 \mathrm{kV}$. For each of the coldrolled, 500, 600, 625 and $650^{\circ} \mathrm{C}$ conditions, bright-field and selected area electron diffraction patterns were collected on 2-3 thin foils per condition. The thickness of the twins $(w)$ in the TEM micrographs was estimated from the measured spacing $\left(\mathrm{w}_{\mathrm{L}}\right)$ using the equation [30]:

$\mathrm{w}=\left(2 \mathrm{w}_{\mathrm{L}}\right) / \pi$

\section{Results and discussion}

\subsection{Changes in microstructure upon isochronal annealing}

The variation in hardness (and the softened fraction calculated using Eq. (1)) and the evolution of microstructure with annealing temperature are shown in Figs. 1 and 2, respectively. The hardness curve can be sub-divided into three regions comprising: (i) a small decline between cold-rolling and annealing at $500{ }^{\circ} \mathrm{C}$ (Figs. 2a, 2b), (ii) a relatively large decrease upon annealing between 600 and 650 ${ }^{\circ} \mathrm{C}$ (Figs. 2c-2e) and (iii) a gradual reduction upon annealing between 700 and $850{ }^{\circ} \mathrm{C}$ (Figs. 2f-2i).

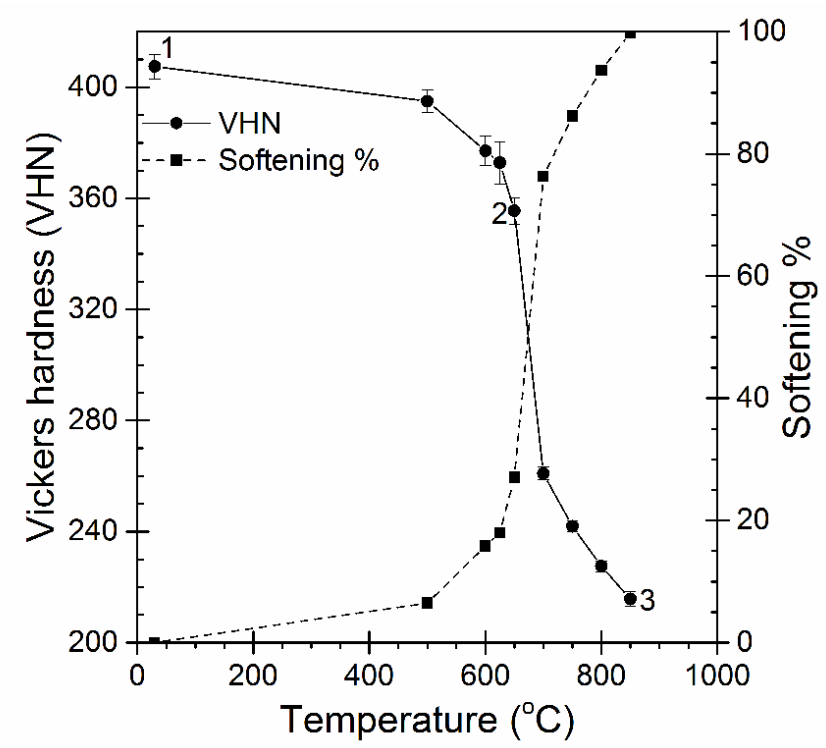

Figure 1: Variation in hardness and the softened fraction with annealing temperature. 
The cold-rolled microstructure comprises elongated, fragmented $\alpha^{\prime}$-martensite as the major phase fraction along with remnant $\varepsilon$-martensite and a trace amount of untransformed $\gamma$ (Fig. 2a). Similar results are obtained when the same steel was cold-rolled to $66 \%$ thickness reduction $[5,6,19]$. During cold-rolling, the $\gamma$ grains undergo subdivision and phase transformation to $\varepsilon$-martensite and $\alpha^{\prime}$ martensite. Furthermore, the thick $\varepsilon$-martensite plates carried over from hot-rolling also transform to $\alpha^{\prime}$-martensite [27]. The delayed transformation of unfavourably oriented $\gamma$ grains to $\varepsilon$-martensite and the sub-division of thick $\varepsilon$-martensite plates by $\alpha^{\prime}$-martensite leads to the presence of $\gamma$ and $\varepsilon$ martensite pockets in the cold-rolled sample (Fig. 2a).

Annealing at $500{ }^{\circ} \mathrm{C}$ shows that the process of reversion back to $\gamma$ is underway (Fig. $2 \mathrm{~b}$ ); with $\Sigma 3$ twins observed in some reverted/recovered $\gamma$ grains (see inset in Fig. 2b). Annealing at 600 and $625{ }^{\circ} \mathrm{C}$ returns a microstructure comprising approximately equal fractions of $\alpha^{\prime}$-martensite and reverted/recovered and recrystallised $\gamma$ (Figs. 2c and 2d). Annealing at $650{ }^{\circ} \mathrm{C}$ results in a mix of recrystallised and polygonised $\gamma$ grains along with some reverted/recovered $\gamma$ and remnant $\alpha^{\prime}$ martensite (Fig. 2e).

Annealing at $700{ }^{\circ} \mathrm{C}$ marks the end of $\gamma$ recrystallisation along with the formation of annealing twins (in yellow, Fig. 2f) and plate-like $\varepsilon$-martensite on quenching. Further annealing between 750 and 850 ${ }^{\circ} \mathrm{C}$ results in ever larger $\gamma$ grains (Figs. $2 \mathrm{~g}$-2i) and a proliferation of plate-like $\varepsilon$-martensite and lenticular/plate-like $\alpha^{\prime}$-martensite forming on quenching (Figs. 2c, 2d, 2f-2i). The increase in $\varepsilon$ and $\alpha^{\prime}$ martensite fraction is ascribed to the higher number of nucleation sites for their formation and the availability of large $\gamma$ grain area for growth in coarser $\gamma$ grain sizes. Also, the low $\gamma$-stacking fault energy of the present high Mn steel (SFE $=14.5 \mathrm{~mJ} / \mathrm{m}^{2}$ [31]) favours the formation of $\varepsilon$ and $\alpha^{\prime}$ martensite. Similar trends increases in $\varepsilon$ and $\alpha^{\prime}$-martensite volume fraction with $\gamma$ grain size have been observed in Ref. [32].

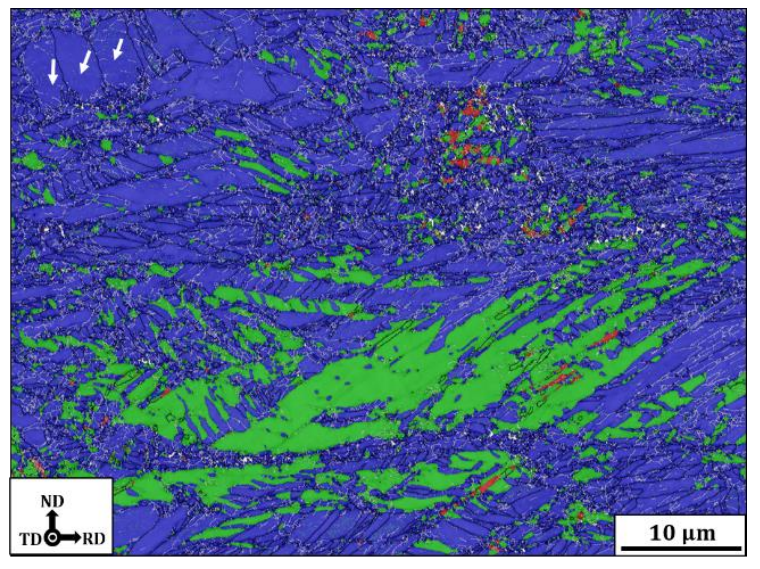

(a)

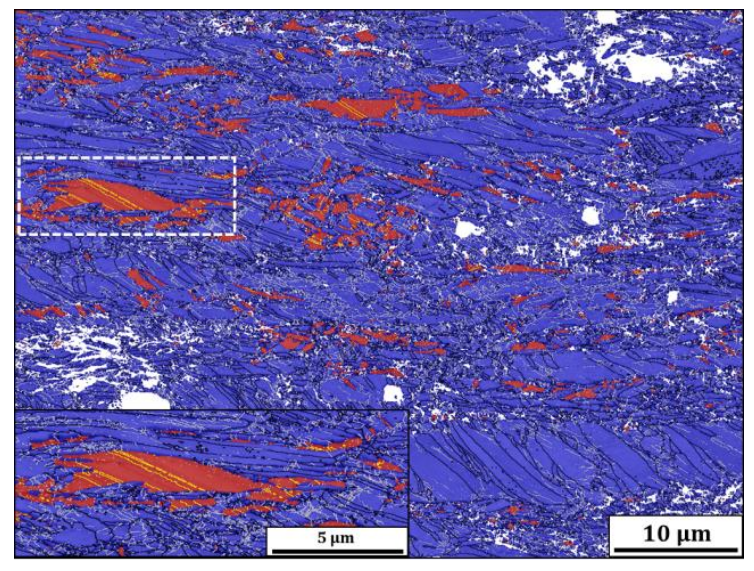

(b) 


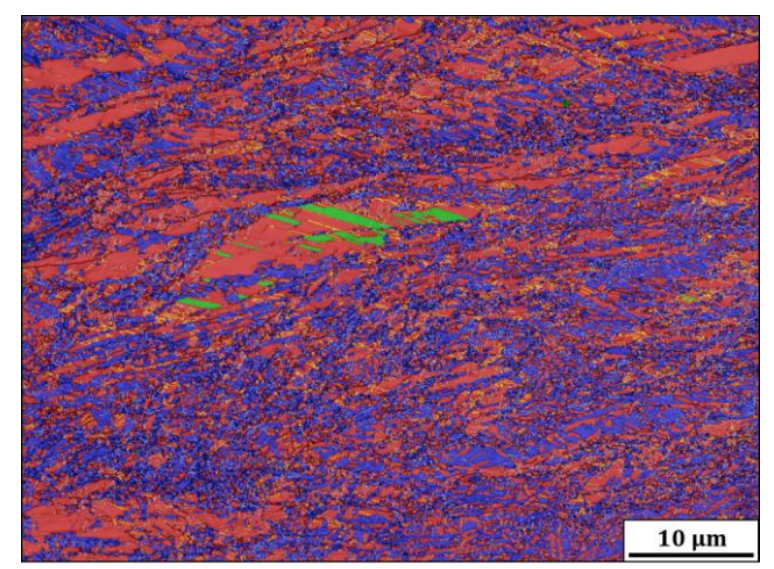

(c)

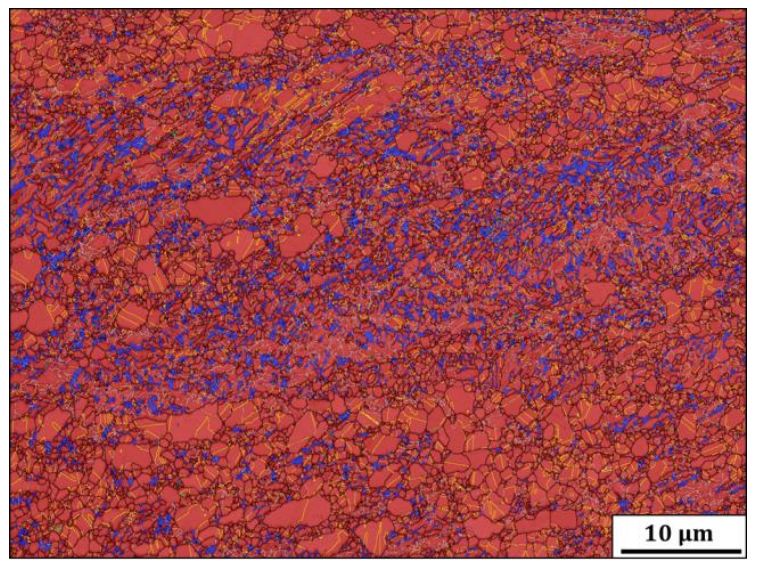

(e)

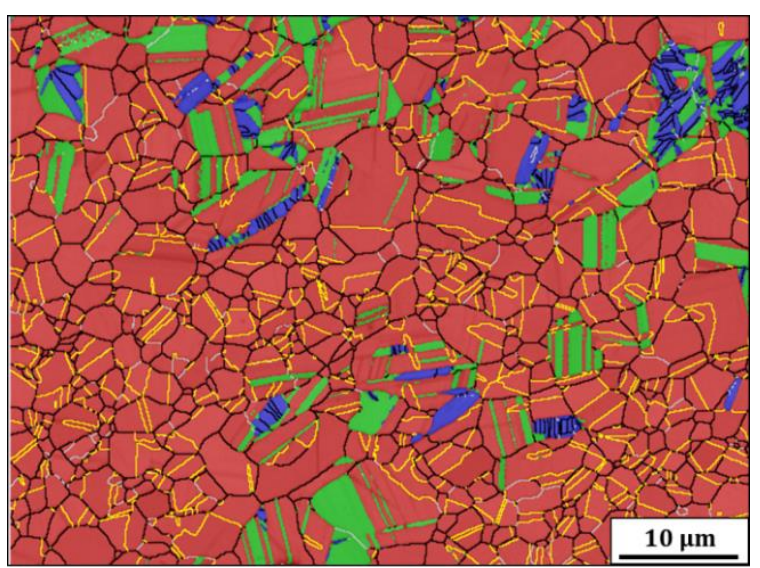

(g)

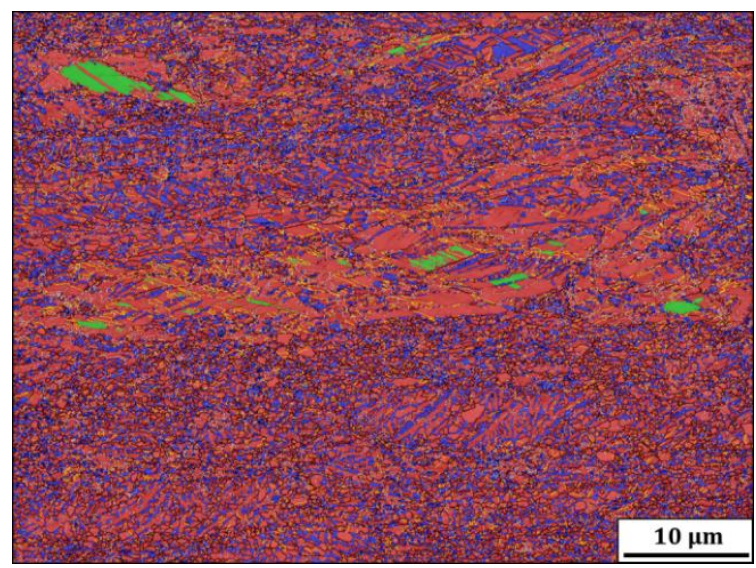

(d)

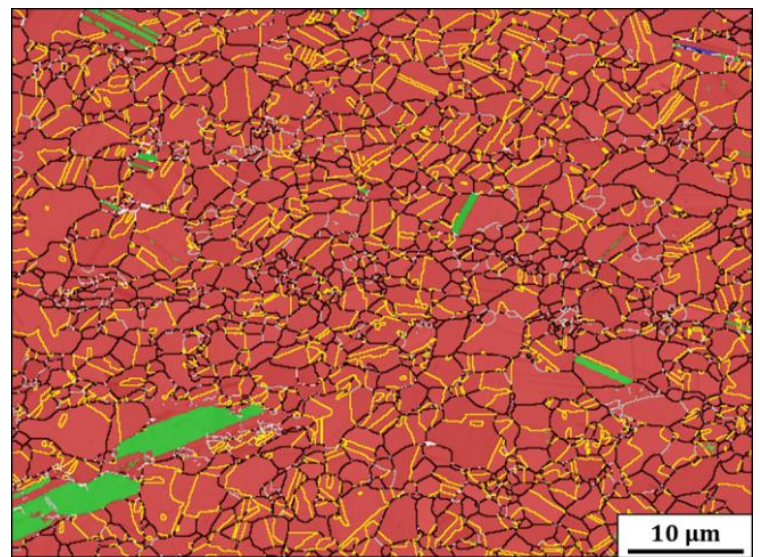

(f)

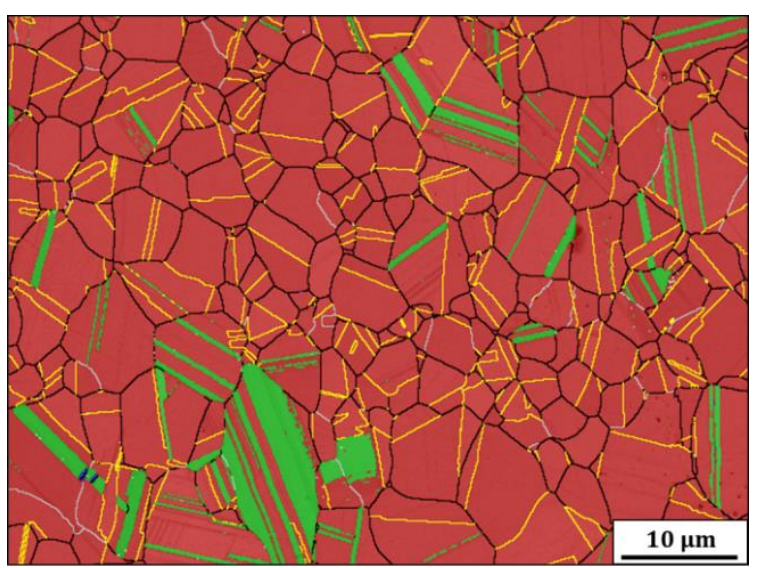

(h)

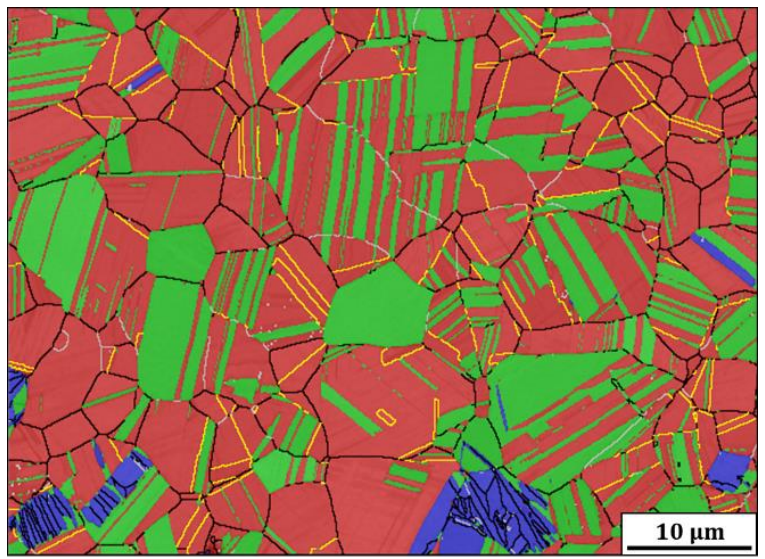


Figure 2: Superimposed band contrast and phase maps after (a) cold-rolling and subsequent annealing at (b) $500{ }^{\circ} \mathrm{C}$, (c) $600{ }^{\circ} \mathrm{C}$, (d) $625^{\circ} \mathrm{C}$, (e) $650{ }^{\circ} \mathrm{C}$, (f) $700{ }^{\circ} \mathrm{C},(\mathrm{g}) 750{ }^{\circ} \mathrm{C}$, (h) $800{ }^{\circ} \mathrm{C}$ and (i) 850 ${ }^{\circ} \mathrm{C}$. Red $=\gamma$, green $=\varepsilon$-martensite, blue $=\alpha^{\prime}$-martensite, white $=$ unindexed areas, silver $=$ LAGBs, black $=$ HAGBs, yellow $=\gamma$ twin boundaries. Rolling direction (RD) $=$ horizontal. Inset in Fig. $2 \mathrm{~b}$ shows twins in reverted/recovered $\gamma$ grain. White arrows in Fig. 2a show the sub-division of $\alpha^{\prime}$-martensite grains.

Figs. 3a-3c depict the $\gamma$ grains segmented using the procedure described in section 2 into reverted/recovered (in green) and recrystallised (in fuschia) fractions after annealing at 600, 625 and $650{ }^{\circ} \mathrm{C}$, respectively. The average grain size of the recrystallised $\gamma$ fraction increased from $0.21 \pm 0.1$ $\mu \mathrm{m}$ to $0.23 \pm 0.11 \mu \mathrm{m}$ to $0.33 \pm 0.25 \mu \mathrm{m}$ upon annealing at 600,625 and $650{ }^{\circ} \mathrm{C}$, respectively. Fig. $3 \mathrm{~d}$ records a decreasing trend in the low-angle boundary population of the reverted/recovered and recrystallised fractions. On the other hand, small decreases and increases in the high-angle boundary population are noted for the reverted/recovered and recrystallised fractions, respectively. As one EBSD map was undertaken per condition, error bars are missing in the segmented $\gamma$ LAGB and HAGB fractions in Fig. 3d.

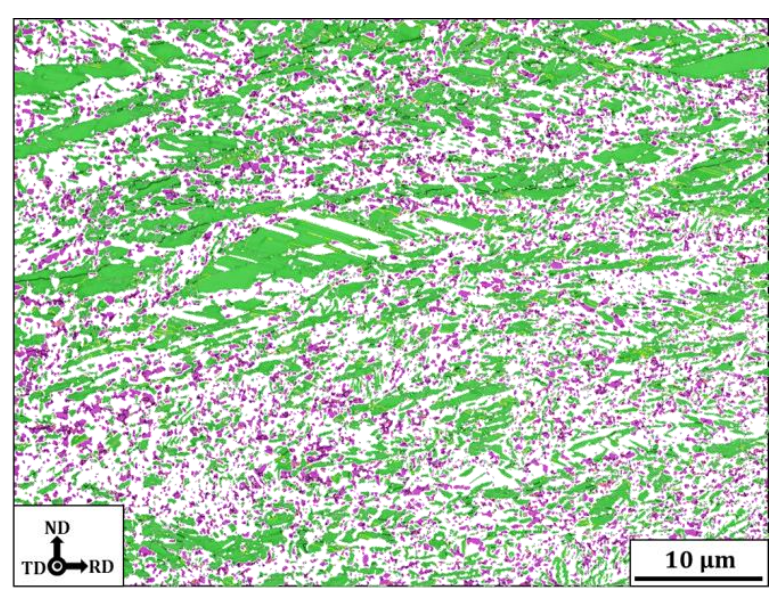

(a)

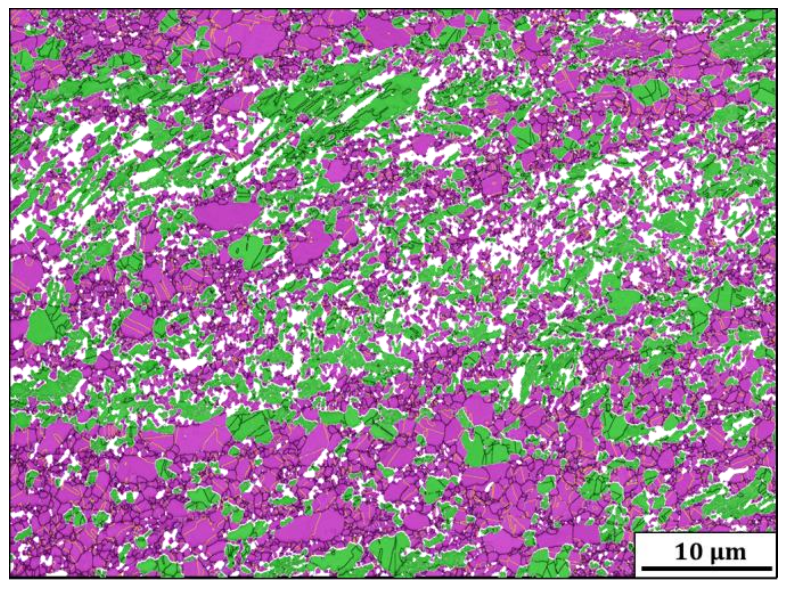

(c)

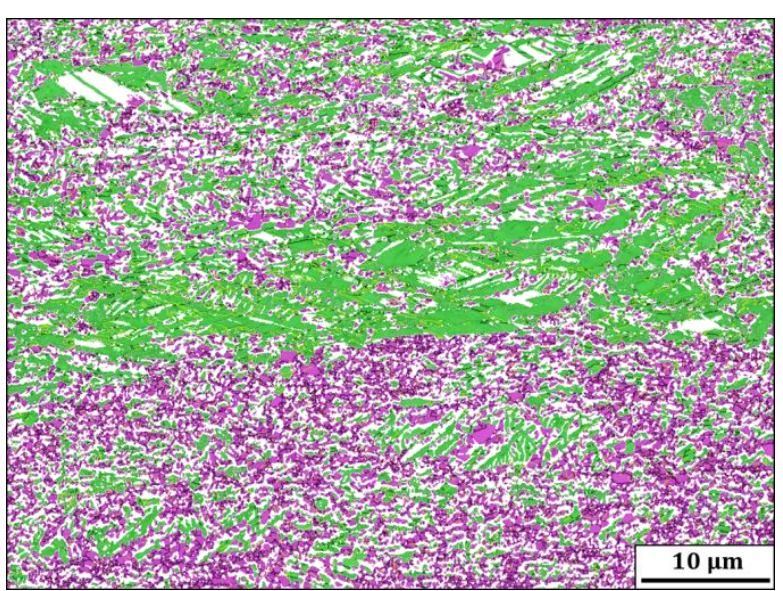

(b)

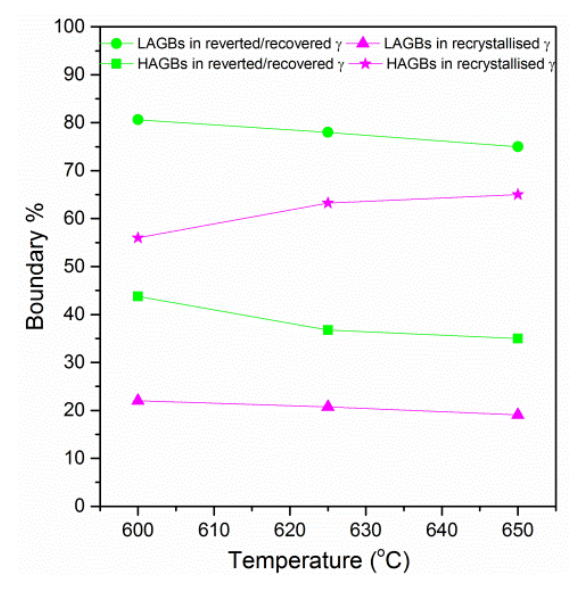

(d) 
Figure 3: $\gamma$ grains segmented into reverted/recovered (in green), recrystallised (in fuschia) fractions after annealing at (a) $600{ }^{\circ} \mathrm{C}$, (b) $625^{\circ} \mathrm{C}$ and (c) $650{ }^{\circ} \mathrm{C}$, (d) the variation of $\gamma$ low angle and high angle grain boundaries percentages with annealing temperature. White regions in Figs. 3a-3c indicate $\varepsilon$ and $\alpha^{\prime}$-martensite as well as unindexed pixels.

In Fig. 4, representative bright field micrographs provide more details on the changes occurring in the cold-rolled microstructure upon annealing at 500,600, 625 and $650{ }^{\circ} \mathrm{C}$. The cold-rolled micrographs show elongated $\alpha^{\prime}$-martensite grains (Fig. 4a); $\varepsilon$-martensite grains containing stacking faults (green arrows, Fig. 4b) along with untransformed $\gamma$ (red arrows, Fig. 4b). In this regard, in-situ neutron diffraction and combined TEM/TKD results by Saleh and Gazder et al. [5, 6, 33] showed the feasibity of deformation accommodation in $\varepsilon$-martensite. In an following detailed TEM study, $\varepsilon$-martensite was found to accommodate deformation via the formation and change in stacking fault character when the steel is progressively cold-rolled up to $42 \%$ thickness reduction [27]. A mechanism enabling the change in stacking fault character was proposed which involves the motion of Shockley partial dislocations on every plane below the stacking fault plane.

Upon annealing between 500 and $650{ }^{\circ} \mathrm{C}$, the formation of fine twins of $\sim 6.5 \pm 4.2 \mathrm{~nm}$ thickness in reverted/recovered $\gamma$ grains is noted; with verification provided by the top left inset diffraction pattern in Fig. 4c. Twins in reverted $\gamma$ grains were previously reported in an Fe-26Mn-3Si-3Al steel cold-rolled to $52 \%$ thickness reduction and annealed at $500{ }^{\circ} \mathrm{C}$ for $30 \mathrm{~min}$ [7]. However, in that study, no reasons were put forward for their formation.

In this regard, a TEM-based in-situ heating investigation of the present $42 \%$ cold-rolled steel observed twin formation in reverted/recovered $\gamma$ grains and attributed the phenomenon to the subsequent recovery of the $\gamma$ grain after it reverts from $\varepsilon$-martensite [34]. Similar recovery-induced twins were observed in $\gamma$ grains reverted from twinned $\alpha^{\prime}$-martensite during the annealing of a Fe-33.5Ni alloy [35]. The nucleation of new $\gamma$ grains at the boundary of reverted/recovered $\gamma$ grains is observed after $600^{\circ} \mathrm{C}$ annealing and shown in the top right inset in Fig. $4 \mathrm{~d}$.

The bottom inset diffraction pattern in Fig. $4 \mathrm{~b}$ depicts the S-N orientation relationship between neighbouring deformation-induced $\varepsilon$-martensite and remnant $\gamma$ grains after cold-rolling. Alternatively, the bottom inset diffraction patterns in Figs. 4c-4e show the K-S orientation relationship between neighbouring remnant $\alpha^{\prime}$-martensite and reverted/recovered $\gamma$ grains upon annealing. 


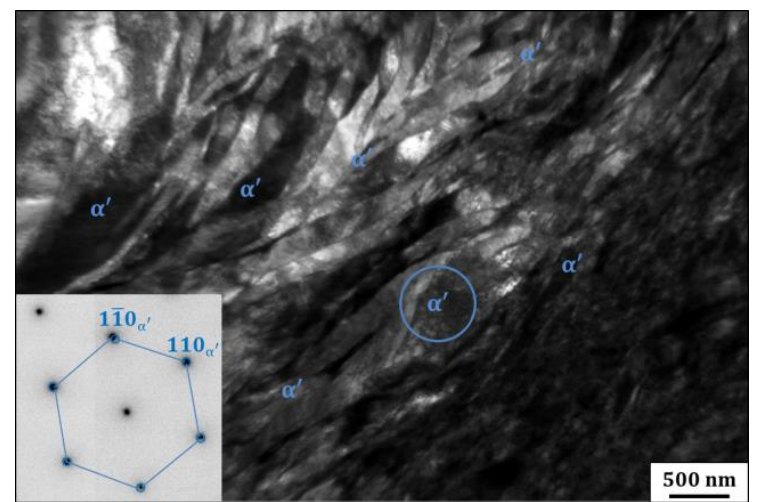

(a)

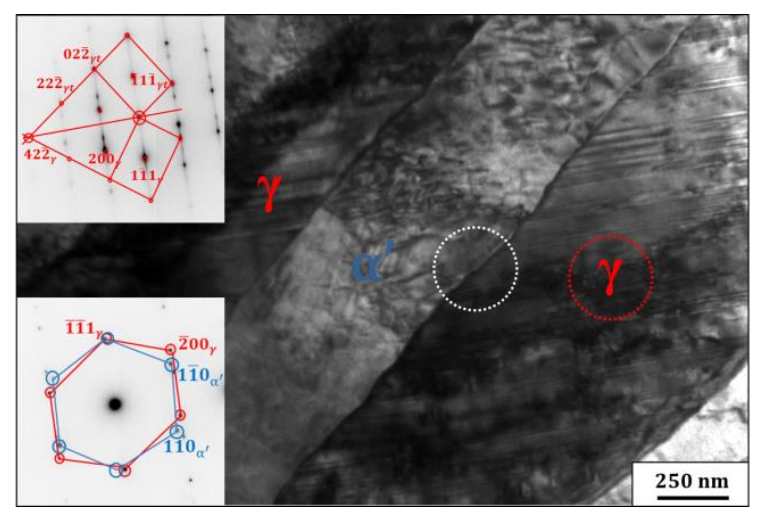

(c)

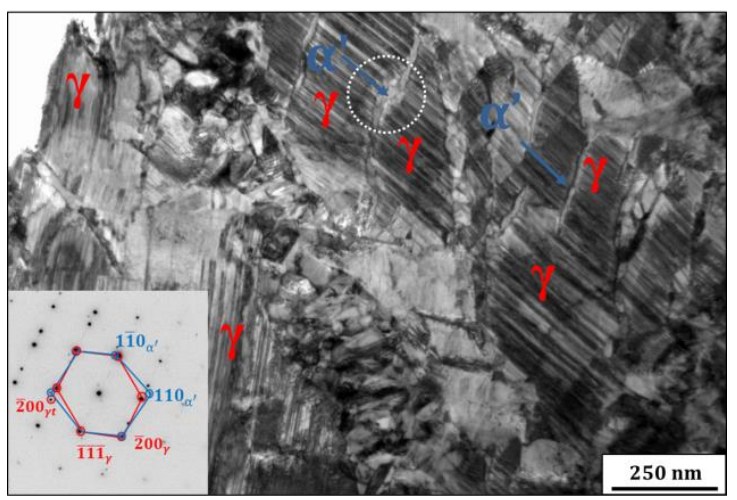

(e)

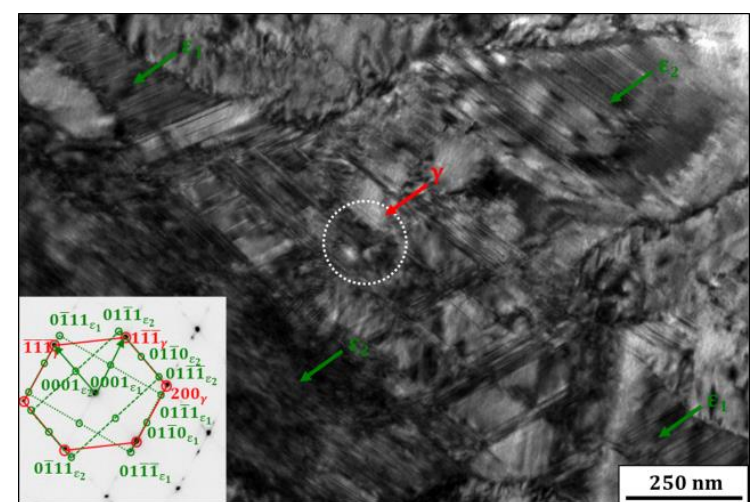

(b)

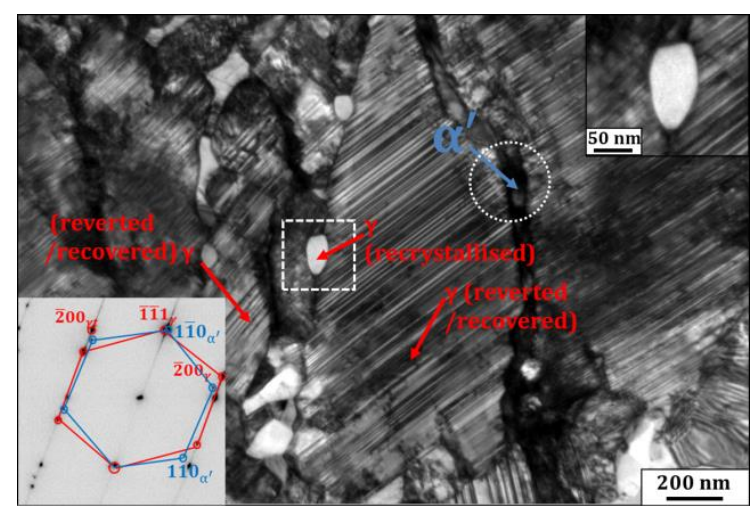

(d)

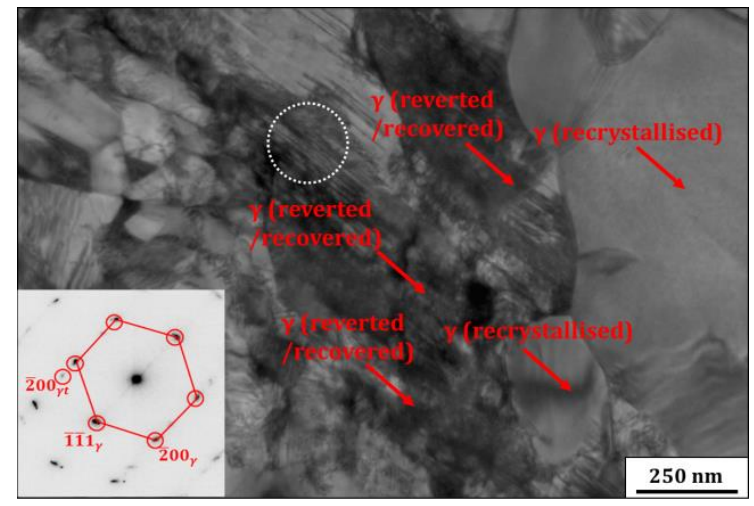

(f)

Figure 4: Representative (a-f) bright-field transmission electron micrographs after (a,b) cold-rolling and annealing at (c) $500{ }^{\circ} \mathrm{C}$, (d) $600^{\circ} \mathrm{C}$, (e) $625^{\circ} \mathrm{C}$ and (f) $650{ }^{\circ} \mathrm{C}$. The bottom left inset diffraction patterns in Figs. 4a-4f are from the regions delineated by white circles. The top left inset diffraction pattern in Fig. $4 \mathrm{c}$ is from the red circular region. Zone axes are $[111]_{\alpha^{\prime}}$ in Fig. $4 \mathrm{a},[2 \overline{1} \overline{1} 0]_{\varepsilon},[110]_{\gamma}$ in Fig. 4b, $[01 \overline{1}]_{\gamma,}$ $[11 \overline{1}]_{\alpha^{\prime}}$ in Figs. 4c-4e and $[110]_{\gamma}$ in Fig. 4f.

\subsection{Changes in texture upon isochronal annealing}

Figs. 5-8 are selected $\phi_{2}$ sections of the orientation distribution functions (ODFs) of $\alpha^{\prime}$ and $\varepsilon$ martensite and $\gamma$ after cold-rolling and annealing. Since $\alpha^{\prime}$ and $\varepsilon$-martensite constitute the predominant the phases in the cold-rolled sample, their ODFs are presented first followed by ODFs of the $\gamma$-phase that forms on reversion during annealing. 
The ODFs of $\gamma, \varepsilon$ and $\alpha^{\prime}$-martensite for the hot-rolled sample are shown in supplementary Fig. S2. Furthermore, the discussion in the following paragraphs is limited to conditions that are representative of significant changes in the microstructure. In this regard, the ODFs after cold-rolling and annealing at $650{ }^{\circ} \mathrm{C}$ and $850{ }^{\circ} \mathrm{C}$ were selected and correspond to points (1-3) in Fig. 1. They are representative of microstructures comprising: (i) deformation-induced $\varepsilon$ and $\alpha^{\prime}$-martensite and remnant $\gamma$ after cold-rolling (Fig. 2a), (ii) remnant $\alpha^{\prime}$-martensite and recovered/recrystallised $\gamma$ after annealing at $650{ }^{\circ} \mathrm{C}$ (Fig. 2e) and, (iii) polygonised $\gamma$, plate-like $\varepsilon$-martensite and plate/lenticular $\alpha^{\prime}$ martensite after annealing at $850{ }^{\circ} \mathrm{C}$ (Fig. 2i). The $650{ }^{\circ} \mathrm{C}$ map (Figs. $2 \mathrm{~d}$ and $3 \mathrm{~b}$ ) was chosen as representative of $\gamma$ grain segmentation in order to compare the micro-texture of the reverted/recovered and recrystallised fractions.

The reader is provided with the complete set of ODFs for all annealing conditions and segmented maps in the supplementary section in Figs. S3-S7. The $\varepsilon$-martensite ODFs after annealing at 500 and $650{ }^{\circ} \mathrm{C}$ are not shown on account of their low area fraction.

Fig. 5 depicts the $\phi_{2}=0^{\circ}$ and $45^{\circ}$ ODF sections of $\alpha^{\prime}$-martensite. Fig. 5 a is a schematic with the ideal $\alpha^{\prime}$-martensite orientations and fibres shown in blue. The $\alpha^{\prime}$-martensite orientations that form upon phase transformation of particular $\gamma$ and $\varepsilon$-martensite orientations via the K-S and Burgers $\left(\{0001\}_{\varepsilon} \|\right.$ $\{110\}_{\alpha^{\prime}},\langle 11 \overline{2} 0\rangle_{\varepsilon} \|\langle 1 \overline{1} 1\rangle_{\alpha^{\prime}}$ ) orientation relationships are shown in red and green, respectively. Similar bcc ODF sections correlating fcc to bcc orientations formed upon phase transformation by the K-S orientation relationship have been reported [36,37]. Indexing the selected area diffraction patterns (Figs. 4c-4e) showed the prevalence of the K-S orientation relationship between reverted/recovered $\gamma$ and $\alpha^{\prime}$-martensite. Thus, only the K-S orientation relationship was chosen for the texture analysis of $\gamma$ and $\alpha^{\prime}$-martensite.

Figs. 5b-5d comprise ODF sections of $\alpha^{\prime}$-martensite after cold-rolling and annealing at 650 and $850{ }^{\circ} \mathrm{C}$, respectively. The deformation-induced $\alpha^{\prime}$-martensite after cold-rolling (Figs. 2a and $5 \mathrm{~b}$ ) and the remnant $\alpha^{\prime}$-martensite after annealing at $650{ }^{\circ} \mathrm{C}$ (Figs. 2e and $5 \mathrm{c}$ ) return relatively stronger intensities along the ideal bcc $\alpha$-fibre $\left(\langle 110\rangle_{\alpha^{\prime}} \| \mathrm{RD}\right)$ centred around (001)[110 $]_{\alpha^{\prime}}$ and weaker intensities along the ideal bcc $\gamma$-fibre $\left(\langle 111\rangle_{\alpha^{\prime}} \| \mathrm{ND}\right)$ spread around the $(111)[\overline{1} \overline{1} 2]_{\alpha^{\prime}}$ and $(554)[\overline{2} \overline{2} 5]_{\alpha^{\prime}}$ orientations. The plate-like/lenticular $\alpha^{\prime}$-martensite formed on quenching after annealing at $850{ }^{\circ} \mathrm{C}$ (Figs. $2 \mathrm{i}$ and $5 \mathrm{~d}$ ) return texture intensities exclusively centred around the $(001)[110]_{\alpha^{\prime}}$ and $(110)[001]_{\alpha^{\prime}}$ orientations. The development of similar orientations has been previously reported in the case of Fe-17Mn-3Al-2Si$1 \mathrm{Ni}-0.06 \mathrm{C}$ steel cold-rolled up to $66 \%$ thickness reduction and subsequently annealed at $625{ }^{\circ} \mathrm{C}[6]$. 


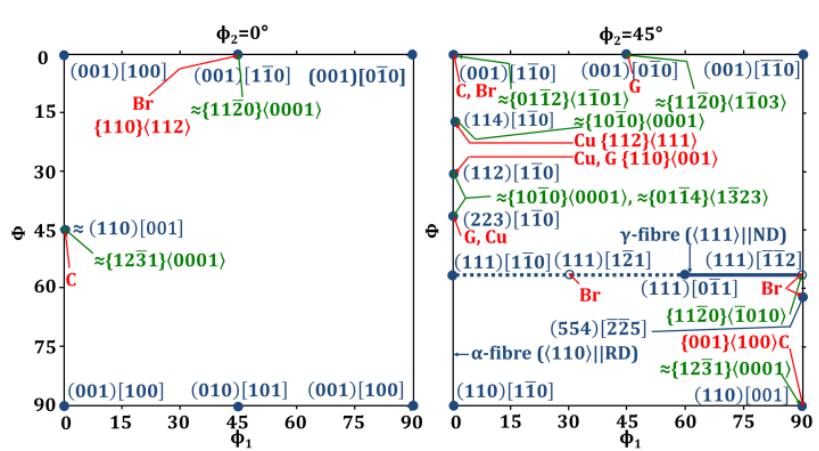

(a)

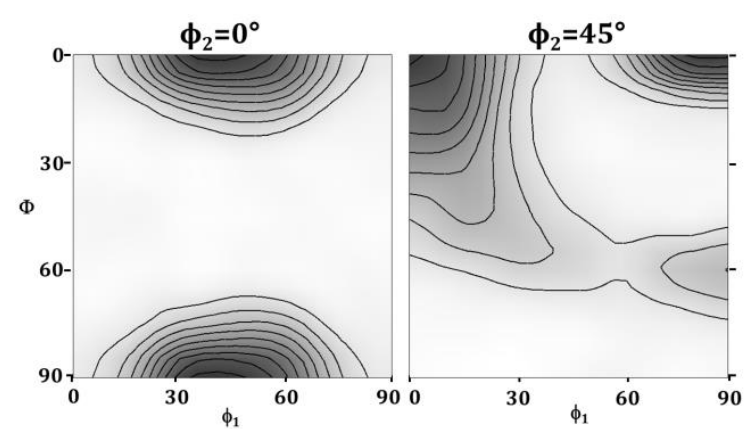

(c)

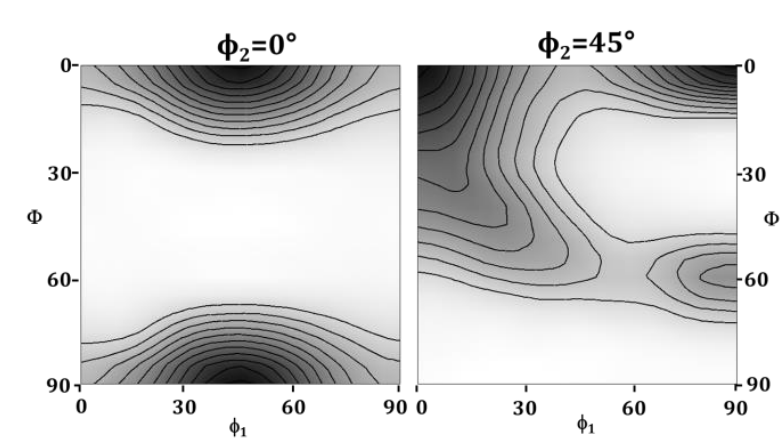

(b)

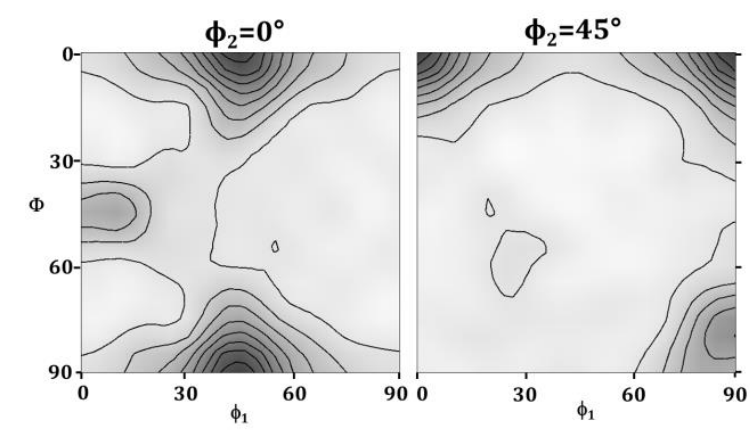

(d)

Figure 5: $\phi_{2}=0^{\circ}$ and $45^{\circ}$ orientation distribution function sections of $\alpha^{\prime}$-martensite showing the (a) ideal orientations (in blue) and after (b) coldrolling, annealing at (c) $650^{\circ} \mathrm{C}$ and (d) $850^{\circ} \mathrm{C}$. In Fig. $5 \mathrm{a}$, particular $\gamma$ (in red) and $\varepsilon$-martensite (in green) orientations are provided for the K-S and Burgers orientation relationships respectively. Contour levels $=0.5 \times$. 
The (001)[110 $]_{\alpha^{\prime}}$ orientation forms upon phase transformation of the ideal $\mathrm{C}_{\gamma}$ and $\mathrm{Br}_{\gamma}$ orientations via the K-S orientation relationship or the transformation of $\{01 \overline{1} 2\}\langle 1 \overline{1} 01\rangle_{\varepsilon}$ via the Burgers orientation relationship. The spread around (111) $[\overline{1} \overline{1} 2]_{\alpha^{\prime}}$ and $(554)[\overline{2} \overline{2} 5]_{\alpha^{\prime}}$ forms upon phase transformation of the ideal $\mathrm{Br}_{\gamma}$ orientation (K-S orientation relationship) or $\{11 \overline{2} 0\}\langle\overline{1} 010\rangle_{\varepsilon}$ (Burgers orientation relationship). Alternatively, the $(110)[001]_{\alpha^{\prime}}$ orientation forms on the phase transformation of $\{12 \overline{3} 1\}\langle 0001\rangle_{\varepsilon}$ via the Burgers orientation relationship.

Fig. 6 shows the $\phi_{2}=0^{\circ}$ and $30^{\circ}$ ODF sections of $\varepsilon$-martensite plotted using the $[10 \overline{1} 0]_{\varepsilon} \| \mathrm{RD}$ and $[0002]_{\varepsilon}$ II ND convention. Fig. 6 a is a schematic with some of the ideal $\varepsilon$-martensite orientations and fibres shown in green. The $\varepsilon$-martensite orientations that form upon phase transformation of particular $\gamma$ orientations (in red) via the S-N orientation relationship are also shown.

Figs. 6b, 6c comprise ODF sections of $\varepsilon$-martensite after cold-rolling and annealing at $850{ }^{\circ} \mathrm{C}$, respectively. The deformation-induced $\varepsilon$-martensite after cold-rolling (Figs. 2a and 6b) shows relatively strong intensities along the $\{h k i l\}_{\varepsilon}$-fibre centred around the $\{\overline{1} 2 \overline{1} 5\}\langle 1 \overline{2} 12\rangle_{\varepsilon}$ and $\{01 \overline{1} 4\}\langle 1 \overline{3} 23\rangle_{\varepsilon}$ orientations and relatively weaker intensities around the $\{10 \overline{1} 0\}\langle 0001\rangle_{\varepsilon}$, $\{11 \overline{2} 0\}\langle 0001\rangle_{\varepsilon}$ and $\{\overline{1} 2 \overline{1} 3\}\langle 10 \overline{1} 0\rangle_{\varepsilon}$ orientations. The $\{h k i l\}_{\varepsilon}$-fibre comprise orientations with their $\{0001\}_{\varepsilon}$ poles deviated by $\sim 24^{\circ}-26^{\circ}$ towards the RD. The formation of this fibre was reported in the Fe-17Mn-3Al-2Si-1Ni-0.06C and Fe-21.6Mn-0.38C steels cold-rolled to $66 \%$ and $50 \%$ thickness reductions respectively $[3,6]$. The plate-like $\varepsilon$-martensite (Figs. $2 \mathrm{i}$ and $6 \mathrm{c}$ ) formed upon quenching after annealing at $850^{\circ} \mathrm{C}$ shows intensities around the $\{01 \overline{1} 2\}\langle 1 \overline{1} 01\rangle_{\varepsilon}$ and $\{\overline{1} 2 \overline{1} 3\}\langle 10 \overline{1} 0\rangle_{\varepsilon}$ orientations. The $\{\overline{1} 2 \overline{1} 5\}\langle 1 \overline{2} 12\rangle_{\varepsilon},\{01 \overline{1} 4\}\langle 1 \overline{3} 23\rangle_{\varepsilon},\{10 \overline{1} 0\}\langle 0001\rangle_{\varepsilon},\{11 \overline{2} 0\}\langle 0001\rangle_{\varepsilon},\{\overline{1} 2 \overline{1} 3\}\langle 10 \overline{1} 0\rangle_{\varepsilon}$ and $\{01 \overline{1} 2\}\langle 1 \overline{1} 01\rangle_{\varepsilon}$ orientations form upon phase transformation of the (213) $[0 \overline{2} 1]_{\gamma},(011)[3 \overline{1} 1]_{\gamma}, \mathrm{Cu}, \mathrm{A}, \sim \mathrm{S}$ and A $\gamma$ orientations via the $\mathrm{S}-\mathrm{N}$ orientation relationship respectively.

Fig. 7 comprises the $\phi_{2}=0^{\circ}, 45^{\circ}$ and $65^{\circ}$ ODF sections of $\gamma$. Fig. 7 a is a schematic with the ideal $\gamma$ orientations and fibres shown in red. The $\gamma$ orientations that form upon phase transformation of particular $\varepsilon$ and $\alpha^{\prime}$-martensite orientations via the S-N and K-S orientation relationships are shown in green and blue, respectively.

Figs. 7b-7d comprise the ODF sections of $\gamma$ after cold-rolling and annealing at 650 and $850{ }^{\circ} \mathrm{C}$, respectively. The untransformed $\gamma$ after cold-rolling (Figs. 2a and 7b) and the reverted, recovered and recrystallised $\gamma$ after annealing at $650{ }^{\circ} \mathrm{C}$ (Figs. 2e and 7c) shows relatively strong intensities along the ideal $\alpha_{\gamma}$-fibre $\left(\langle 110\rangle_{\gamma} \| \mathrm{ND}\right)$ centred around the $\mathrm{Br}_{\gamma}$ orientation with weaker intensities around the $\mathrm{Cu}_{\gamma}, \mathrm{S}_{\gamma}$ and (213) $[0 \overline{2} 1]_{\gamma}$ orientations. The recrystallised $\gamma$ formed after annealing at $850{ }^{\circ} \mathrm{C}$ (Figs. $2 \mathrm{i}$ and $7 d)$ returns weak intensities centred around the ideal Cube $\left(C_{\gamma},\{001\}\langle 100\rangle_{\gamma}\right), A_{\gamma}, \mathrm{Cu}_{\gamma}$ and $S_{\gamma}$ orientations. Similar orientations have been reported in an Fe-17Mn-3Al-2Si-1Ni-0.06C steel subjected to cold-rolling up to $66 \%$ thickness reduction and subsequent annealing at $625{ }^{\circ} \mathrm{C}$ [6]. Higher intensities near the ideal $S_{\gamma}$ orientation have been reported upon the reversion of $\varepsilon$-martensite to $\gamma$ after annealing at $630{ }^{\circ} \mathrm{C}$ for an Fe-22Mn-0.4C steel cold-rolled to $50 \%$ thickness reduction [3]. 
The (i) $\mathrm{Br}_{\gamma}$, (ii) $\mathrm{Cu}_{\gamma}$, (iii) (213)[0리 $]_{\gamma}$ and (iv) $\mathrm{S}_{\gamma}$ orientations form upon phase transformation of the:

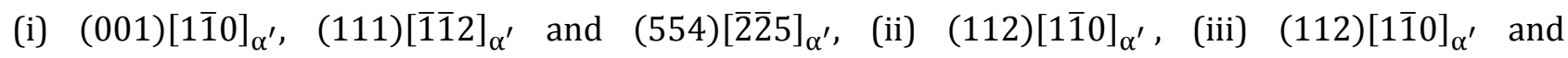
(111) $[\overline{1} \overline{1} 2]_{\alpha^{\prime}}$ and (iv) (001) $[1 \overline{1} 0]_{\alpha^{\prime}}$ orientations via the K-S orientation relationship. Alternatively, the $\mathrm{Br}_{\gamma}, \mathrm{Cu}_{\gamma},(213)[0 \overline{2} 1]_{\gamma}$ and $\mathrm{S}_{\gamma}$ orientation can also form from the $\{11 \overline{2} 0\}\langle 0001\rangle_{\varepsilon},\{10 \overline{1} 0\}\langle 0001\rangle_{\varepsilon}$, $\{\overline{1} 2 \overline{1} 5\}\langle 1 \overline{2} 12\rangle_{\varepsilon}$ and $\{\overline{1} 2 \overline{1} 3\}\langle 10 \overline{1} 0\rangle_{\varepsilon}$ orientations via the S-N orientation relationship, respectively.

Fig. 8 are the ODF sections of the $\gamma$ grains segmented into their reverted/recovered and recrystallised fractions after annealing at $625^{\circ} \mathrm{C}$ (Fig. 3b). The reverted/recovered $\gamma$ fraction shows relatively strong intensities around the (214) $[\overline{1} \overline{2} 1]_{\gamma}$ orientation and relatively weak intensities around the ideal $\mathrm{G}_{\gamma}, \mathrm{Br}_{\gamma}$ orientations. The recrystallised $\gamma$ fraction retains similar orientations with relatively weaker intensities compared to their reverted/recovered fraction counterparts. Similar $\gamma$ recrystallisation behaviour was reported upon annealing of metastable austenitic steels [38, 39].

\subsection{Changes in mechanical properties upon isochronal annealing}

Fig. 9 shows the engineering stress-strain curves of the cold-rolled and annealed samples with the tensile properties listed in Table 1 . After cold-rolling and annealing at $500{ }^{\circ} \mathrm{C}$, the yield stress (here, the $0.2 \%$ proof stress) is $1080 \mathrm{MPa}$ and $1075 \mathrm{MPa}$, respectively, along with total elongations of $\sim 0.02$ engineering strain. The low elongation is due to the inability of the $\alpha^{\prime}$-martensite fraction to accommodate further deformation due to prior cold-rolling and incomplete recovery upon annealing at $500{ }^{\circ} \mathrm{C}$, respectively.

In contrast, the engineering stress-strain curves after annealing at 625 and $650{ }^{\circ} \mathrm{C}$ return entirely different shapes. These conditions comprise an initial microstructure of remnant $\alpha^{\prime}$-martensite and reverted/recovered and recrystallised $\gamma$; which upon tension, return yield stresses of $810 \mathrm{MPa}$ and $732 \mathrm{MPa}$, respectively. This is followed by an approximately linear rise in engineering stress-strain values up to ultimate tensile strengths of 1006 and $976 \mathrm{MPa}$ after annealing at 625 and $650^{\circ} \mathrm{C}$, respectively. These results are similar to other high manganese steels comprising initial dual phase microstructures [40].

After annealing at 700 and $800{ }^{\circ} \mathrm{C}$, the initial microstructure comprises recrystallised $\gamma$ with plate-like $\varepsilon$-martensite and plate/lenticular $\alpha^{\prime}$-martensite formed upon quenching. During uniaxial tension, these conditions return yield stresses of $465 \mathrm{MPa}$ and $360 \mathrm{MPa}$, respectively, which are lower than to the previous annealing conditions. This is followed by a slow rising stress region (inflexion point) up to ultimate tensile strengths of $856 \mathrm{MPa}$ and $827 \mathrm{MPa}$, respectively. An Fe-15Mn-3Al-3Si steel annealed at $1000{ }^{\circ} \mathrm{C}$ for $2 \mathrm{~h}$ shows a very similar engineering stress-strain curve with the inflexion point correlated to the inception of deformation-induced phase transformations. The intersection of the linearly extrapolated elastic modulus and the tangent drawn from the slow rising stress region is defined as the triggering stress [41] and was estimated as $\sim 518 \mathrm{MPa}$ and $\sim 419 \mathrm{MPa}$ after annealing at 700 and $800{ }^{\circ} \mathrm{C}$, respectively. 


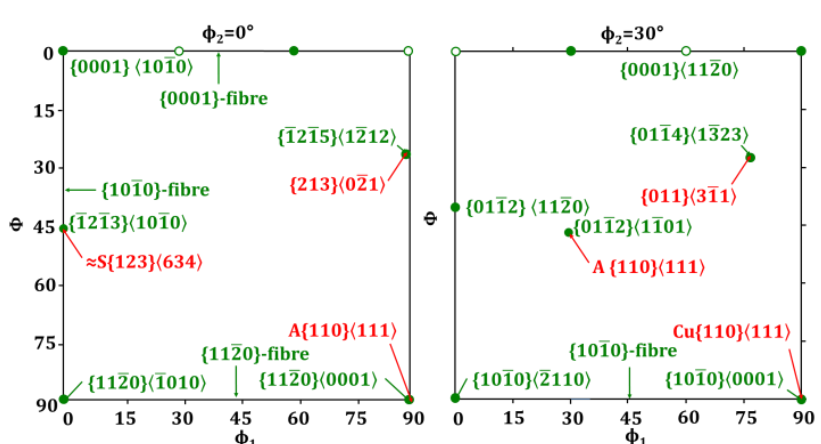

(a)

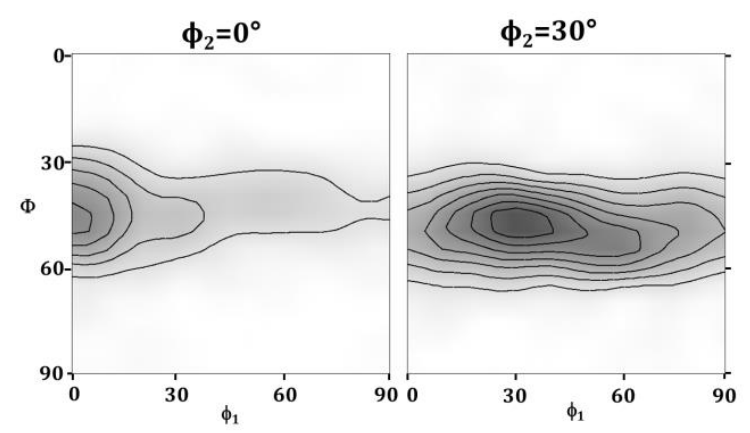

(c)

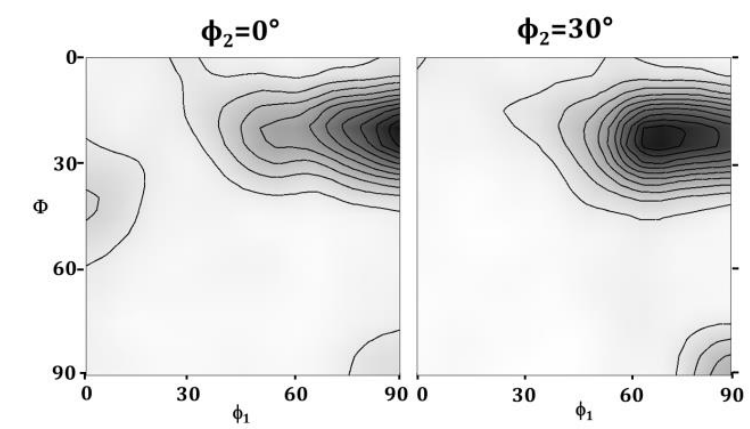

(b)

Figure 6: $\phi_{2}=0^{\circ}$ and $30^{\circ}$ orientation distribution function sections of $\varepsilon$-martensite showing (a) ideal orientations (in green) and after (b) coldrolling, (c) annealing at $850^{\circ} \mathrm{C}$. In Fig. 6a, particular $\gamma$ orientations (in red) are provided for the S-N orientation relationship. Contour levels $=0.5 \times$ 


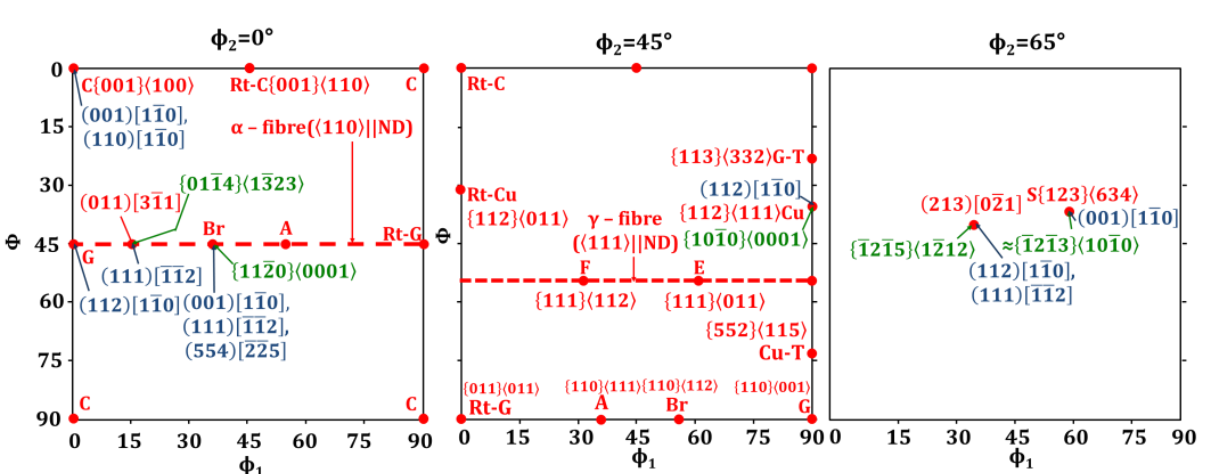

(a)

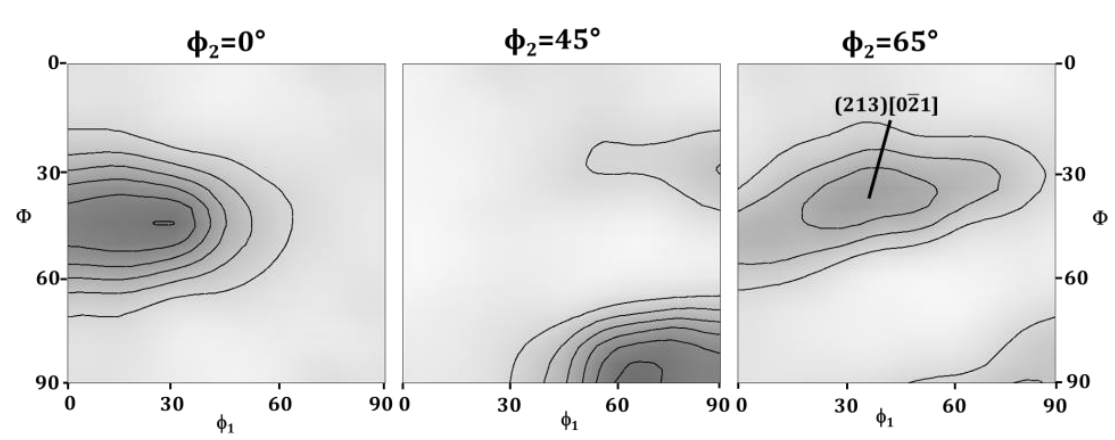

(c)

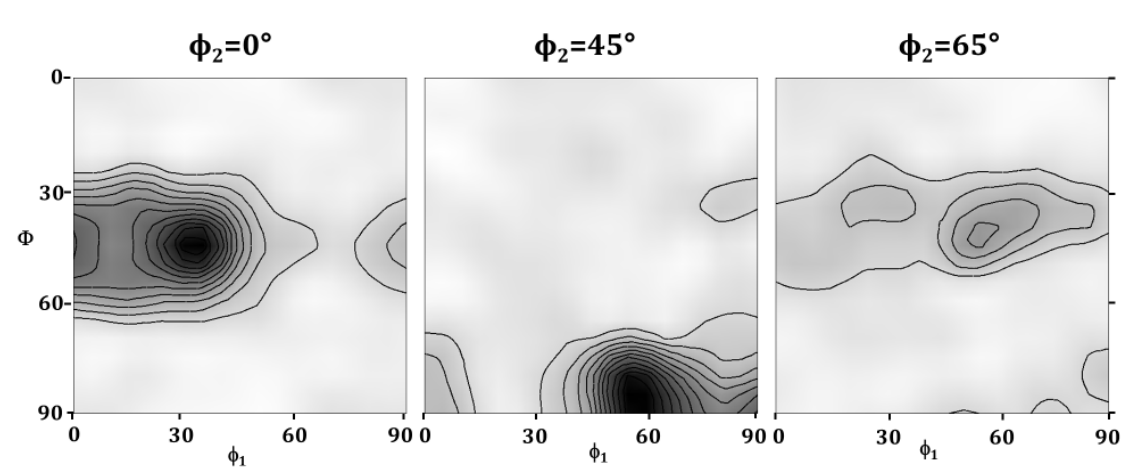

(b)

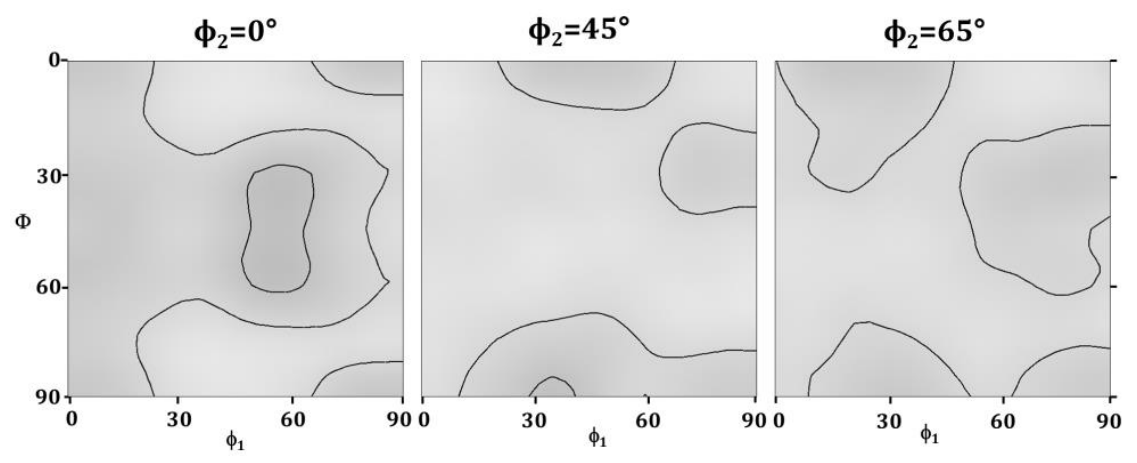

(d)

Figure 7: $\phi_{2}=0^{\circ}, 45^{\circ}$ and $65^{\circ}$ orientation distribution function sections of $\gamma$ showing (a) ideal orientations (in red) and after (b) cold-rolling and annealing at (c) $650^{\circ} \mathrm{C}$ and (d) $850^{\circ} \mathrm{C}$. In Fig. 7a, particular $\varepsilon$-martensite (in green) and $\alpha^{\prime}$-martensite (in blue) orientations are provided for the S-N and $\mathrm{K}-\mathrm{S}$ orientation relationships respectively. Contour levels $=0.5 \times$. 


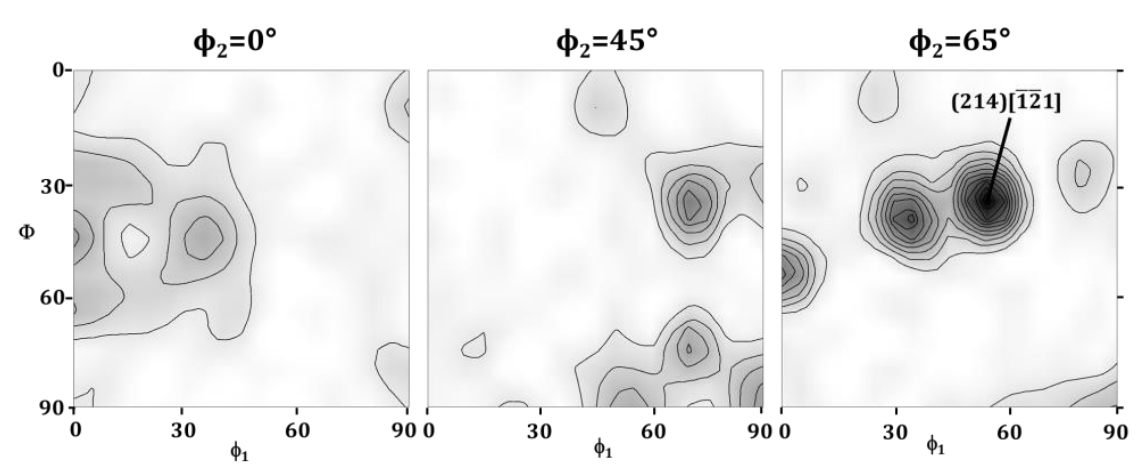

(a)

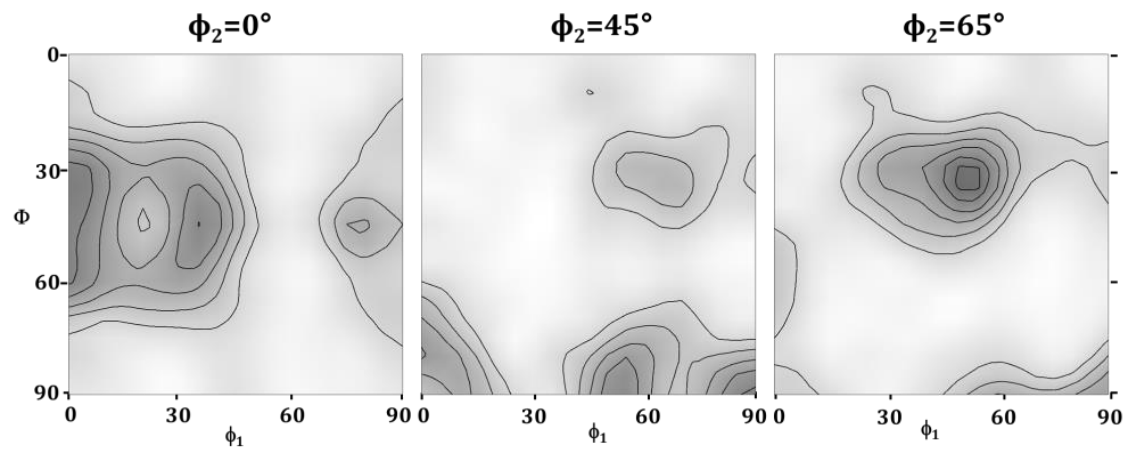

(b)

Figure 8: $\phi_{2}=0^{\circ}, 45^{\circ}$ and $65^{\circ}$ orientation distribution function sections of $\gamma$ grains segemeted into (a) reverted/recovered and (b) recrystallised fractions after annealing at $(\mathrm{a}, \mathrm{b}) 625^{\circ} \mathrm{C}$. Contour levels $=0.5 \times$. 
The unique shape of the engineering stress-strain curves after annealing at 625 and $650{ }^{\circ} \mathrm{C}$ is due to the load partitioning between $\gamma$, pre-existing $\varepsilon$ and $\alpha^{\prime}$-martensite [40] and the additional transformation of $\gamma$ to deformation-induced $\varepsilon$ and $\alpha^{\prime}$-martensite. The yield stress after annealing at $800{ }^{\circ} \mathrm{C}$ is lower than after annealing at $700{ }^{\circ} \mathrm{C}$ due to $\gamma$ grain coarsening from $1.9 \pm 1.4 \mu \mathrm{m}$ to $4.3 \pm 2.7$ $\mu \mathrm{m}$ [19]. Tomota et al. [42] reported a higher yield stress for annealed samples having a relatively coarse $\gamma$ grain size due to the higher fraction of plate-like $\varepsilon$-martensite formed on quenching. However, in the present study, annealing at $800{ }^{\circ} \mathrm{C}$ returns a higher fraction of $\varepsilon$ and $\alpha^{\prime}$-martensite and a lower yield strength than after annealing at $700{ }^{\circ} \mathrm{C}$.

Alternatively, the total elongation is the largest after annealing at $700{ }^{\circ} \mathrm{C}$. This due to the higher $\gamma$ area fraction available for phase transformation to deformation-induced $\varepsilon$ and $\alpha^{\prime}$-martensite leading to larger total elongation. The total elongation obtained after annealing at $800{ }^{\circ} \mathrm{C}$ is lower than the above condition on account of the relatively higher fractions of $\varepsilon$ and $\alpha^{\prime}$-martensite and $\gamma-\varepsilon$-martensite and $\gamma$ $\alpha^{\prime}$-martensite interfaces that contribute to the nucleation and coalescence of micro-cracks upon tension [43].

The above results indicate that once $\gamma$ is fully recrystallised and polygonised, the initial $\gamma$ grain size has a more significant effect on yield strength than the $\varepsilon$ and $\alpha^{\prime}$-martensite phase fractions. Alternatively, the initial $\varepsilon$ and $\alpha^{\prime}$-martensite fractions tend to affect the total elongation.

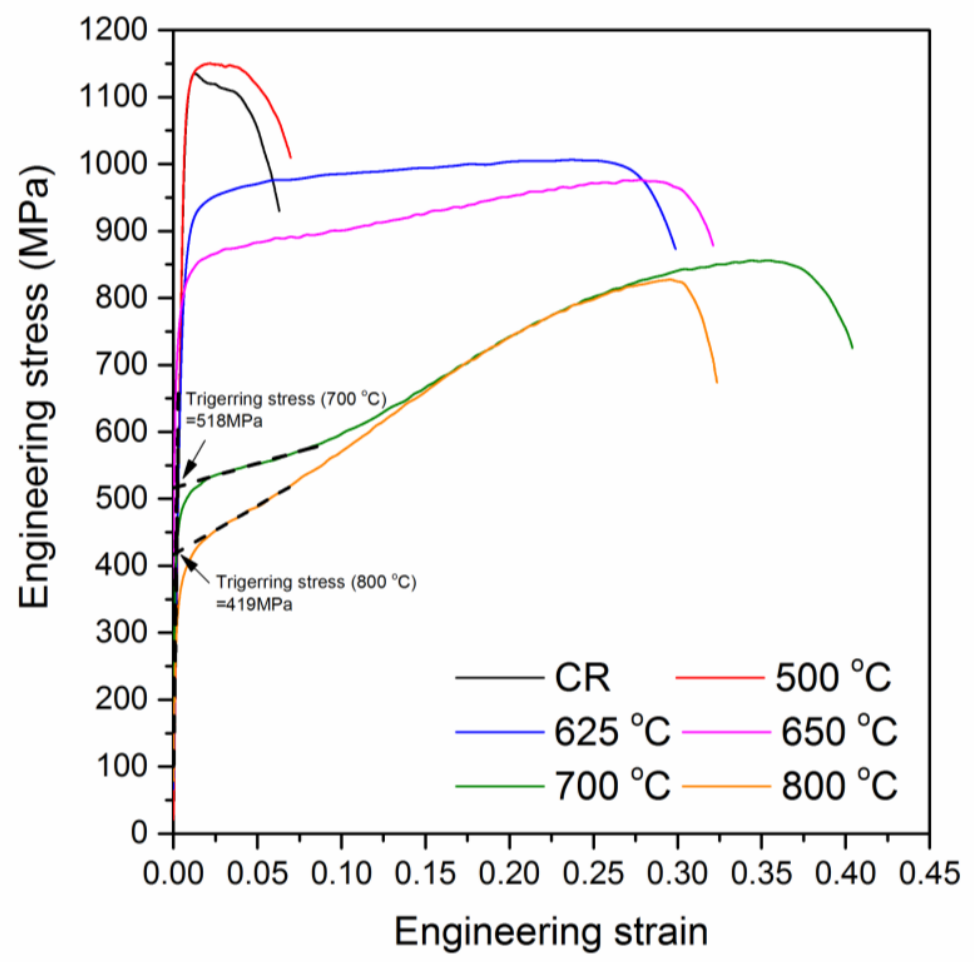

Figure 9: Engineering stress-strain curves after cold-rolling and annealing at 500, 625, 650, 700 and $800{ }^{\circ} \mathrm{C}$. 
Table 1 Engineering tensile properties after cold-rolling and annealing at 500, 625, 650, 700 and 800 ${ }^{\circ} \mathrm{C}$.

\begin{tabular}{|c|c|c|c|c|c|c|}
\hline \multirow{2}{*}{ Tensile properties } & \multicolumn{7}{|c|}{ Sample condition } \\
\cline { 2 - 7 } & Cold-rolled & $500^{\circ} \mathrm{C}$ & $625^{\circ} \mathrm{C}$ & $650^{\circ} \mathrm{C}$ & $700{ }^{\circ} \mathrm{C}$ & $800^{\circ} \mathrm{C}$ \\
\hline Yield strength (MPa) & 1080 & 1075 & 810 & 732 & 465 & 360 \\
\hline Ultimate tensile strength (MPa) & 1135 & 1150 & 1006 & 976 & 856 & 827 \\
\hline Uniform elongation & 0.02 & 0.02 & 0.24 & $\sim 0.28$ & $\sim 0.36$ & $\sim 0.3$ \\
\hline Total elongation & $\sim 0.07$ & $\sim 0.07$ & $\sim 0.3$ & $\sim 0.32$ & $\sim 0.41$ & $\sim 0.33$ \\
\hline
\end{tabular}

\section{Conclusions}

A Fe-17Mn-3Al-2Si-1Ni-0.06C wt.\% steel after 42\% cold-rolling and isochronal annealing for $300 \mathrm{~s}$ between 500 and $850{ }^{\circ} \mathrm{C}$ was characterised via a combination of electron back-scattering diffraction, transmission electron microscopy and uniaxial tensile testing. Upon annealing to $650{ }^{\circ} \mathrm{C}$, the reversion of deformation-induced $\varepsilon$ and $\alpha^{\prime}$-martensite to $\gamma$ is observed with the formation of fine twins in reverted/recovered $\gamma$ grains. Subsequent nucleation of new $\gamma$ grains at the boundaries of reverted/recovered $\gamma$ grains is also noted. The $\gamma$ orientations are obtained from the $\varepsilon$ and $\alpha^{\prime}-$ martensite orientations upon phase transformations via the Shoji-Nishiyama and Kurdjumov-Sachs orientation relationships, respectively. The segmented $\gamma$ grains indicate that the recrystallised $\gamma$ grains nucleate with orientations similar to their reverted/recovered $\gamma$ grain counterparts. Once $\gamma$ recrystallisation is complete, the initial $\gamma$ grain size has a more significant effect on the yield strength than the $\varepsilon$ and $\alpha^{\prime}$-martensite fractions during uniaxial tension. Also, the total elongation upon tension is affected by the initial $\varepsilon$ and $\alpha^{\prime}$-martensite fractions.

\section{Acknowledgements}

The authors are thankful to Prof. D. B. Santos of Universidade Federal de Minas Gerais, Brazil for providing the source material. The authors acknowledge the use of JEOL JSM-7001F FEG-SEM and JEOL JEM-2010 located at the UOW Electron Microscopy Centre purchased with the financial support from Australian Research Council grants LE0882613 and LE0237478, respectively. This work was supported by the Engineering Materials Research Strength at UOW.

Declarations of interest: none.

Data availability: The raw/processed data required to reproduce these findings cannot be shared at this time as the data also forms part of an ongoing study. 


\section{References}

[1] J. Kowalska, W. Ratuszek, M. Witkowska, A. Zielińska-Lipiec, T. Tokarski, Microstructure and texture characteristics of the metastable Fe-21Mn-3Si-3Al alloy after cold deformation, J. Alloy Compd. 643, Supplement 1 (2015) S39-S45.

[2] O. Bouaziz, S. Allain, C.P. Scott, P. Cugy, D. Barbier, High manganese austenitic twinning induced plasticity steels: A review of the microstructure properties relationships, Curr. Opin. Solid St. M. 15(4) (2011) 141-168.

[3] Y. Lü, B. Hutchinson, D.A. Molodov, G. Gottstein, Effect of deformation and annealing on the formation and reversion of $\varepsilon$-martensite in an Fe-Mn-C alloy, Acta Mater. 58(8) (2010) 3079-3090.

[4] F. Lu, P. Yang, L. Meng, F. Cui, H. Ding, Influences of thermal martensites and grain orientations on strain-induced martensites in high Manganese TRIP/TWIP steels, J. Mater. Sci. Technol. 27(3) (2011) 257-265.

[5] A.A. Gazder, A.A. Saleh, A.G. Kostryzhev, E.V. Pereloma, Application of transmission Kikuchi diffraction to a multi-phase TRIP-TWIP steel, Mater. Today: Proc. 2, Supplement 3 (2015) S647-S650.

[6] A.A. Gazder, A.A. Saleh, M.J.B. Nancarrow, D.R.G. Mitchell, E.V. Pereloma, A transmission Kikuchi diffraction study of a cold-rolled and annealed Fe-17Mn-2Si-3Al-1Ni-0.06C wt.\% steel, Steel Res. Int. 86(10) (2015) 1204-1214.

[7] J. Kowalska, W. Ratuszek, M. Witkowska, A. Zielińska-Lipiec, Development of microstructure and texture in Fe-26Mn-3Si-3Al alloy during cold-rolling and annealing, J. Alloy Compd. 615, Supplement 1 (2014) S583-S586.

[8] D. Pérez Escobar, S.S.F. Dafé, D. Brandão Santos, Martensite reversion and texture formation in 17Mn-0.06C TRIP/TWIP steel after hot cold rolling and annealing, J. Mater. Res. Tech. 4(2) (2015) 162170.

[9] Z. Nishiyama, Martensitic transformation, Elsevier Science2012.

[10] G. Kurdjumow, G. Sachs, Über den mechanismus der stahlhärtung, Zeitschrift für Physik A Hadrons and Nuclei 64(5) (1930) 325-343.

[11] G. Frommeyer, U. Brux, P. Neumann, Supra-ductile and high-strength manganese-TRIP/TWIP steels for high energy absorption purposes, ISIJ Int. 43(3) (2003) 438-446.

[12] 0. Grässel, L. Krüger, G. Frommeyer, L. Meyer, High strength Fe-Mn-(Al, Si) TRIP/TWIP steels development—properties—application, Int. J. Plasticity 16(10) (2000) 1391-1409.

[13] S. Pramanik, A.A. Gazder, A.A. Saleh, D.B. Santos, E.V. Pereloma, A digital image correlation study of a metastable high manganese steel subjected to uniaxial tension, Adv. Eng. Mater. (Under review) (2018).

[14] F. Berrenberg, C. Haase, L.A. Barrales-Mora, D.A. Molodov, Enhancement of the strength-ductility combination of twinning-induced/transformation-induced plasticity steels by reversion annealing, Mater. Sci. Eng. A 681 (2017) 56-64. 
[15] P. Behjati, A. Kermanpur, L.P. Karjalainen, A. Järvenpää, M. Jaskari, H. Samaei Baghbadorani, A. Najafizadeh, A. Hamada, Influence of prior cold rolling reduction on microstructure and mechanical properties of a reversion annealed high-Mn austenitic steel, Mater. Sci. Eng. A 650 (2016) 119-128.

[16] H. Ding, Z.-Y. Tang, W. Li, M. Wang, D. Song, Microstructures and mechanical properties of Fe-Mn(Al, Si) TRIP/TWIP steels, Journal of Iron and Steel Research, International 13(6) (2006) 66-70.

[17] B. Huang, X. Wang, Y. Rong, L. Wang, L. Jin, Mechanical behavior and martensitic transformation of an Fe-Mn-Si-Al-Nb alloy, Mater. Sci. Eng. A 438 (2006) 306-311.

[18] A. Sato, K. Soma, T. Mori, Hardening due to pre-existing e-Martensite in an Fe-30Mn-1Si alloy single crystal, Acta Metall. Mater. 30(10) (1982) 1901-1907.

[19] S. Pramanik, A.A. Saleh, D.B. Santos, E.V. Pereloma, A.A. Gazder, Microstructure evolution during isochronal annealing of a 42\% cold rolled TRIP-TWIP steel, IOP C. Ser. 89(1) (2015) 012042.

[20] M.H. Razmpoosh, A. Zarei-Hanzaki, N. Haghdadi, J.-H. Cho, W.J. Kim, S. Heshmati-Manesh, Thermal stability of an ultrafine-grained dual phase TWIP steel, Mater. Sci. Eng. A 638 (2015) 5-14.

[21] S. Nanba, M. Kitamura, M. Shimada, M. Katsumata, T. Inoue, H. Imamura, Y. Maeda, S. Hattori, Prediction of microstructure distribution in the through-thickness direction during and after hot rolling in carbon steels, ISIJ Int. 32(3) (1992) 377-386.

[22] P.D. Hodgson, R.K. Gibbs, A mathematical model to predict the mechanical properties of hot rolled C-Mn and microalloyed steels, ISIJ Int. 32(12) (1992) 1329-1338.

[23] F.J. Humphreys, Recrystallization and related annealing phenomena, Elsevier Science, Cambridge, 2012.

[24] G. Palumbo, K.T. Aust, Structure-dependence of intergranular corrosion in high purity nickel, Acta Metall. Mater. 38(11) (1990) 2343-2352.

[25] J. Chen, W.N. Zhang, Z.Y. Liu, G.D. Wang, Microstructural evolution and deformation mechanism of a Fe-15Mn alloy investigated by electron back-scattered diffraction and transmission electron microscopy, Mater. Sci. Eng. A 698 (2017) 198-205.

[26] J.J. Fundenberger, B. Beausir, JTEX - software for texture analysis, Université de Lorraine - Metz, 2015.

[27] S. Pramanik, A.A. Gazder, A.A. Saleh, E.V. Pereloma, Nucleation, coarsening and deformation accommodation mechanisms of $\varepsilon$-martensite in a high manganese steel, Mater. Sci. Eng. A 731 (2018) 506-519.

[28] A.A. Gazder, V.Q. Vu, A.A. Saleh, P.E. Markovsky, O.M. Ivasishin, C.H.J. Davies, E.V. Pereloma, Recrystallisation in a cold drawn low cost beta titanium alloy during rapid resistance heating, J. Alloy Compd. 585(Supplement C) (2014) 245-259.

[29] A.A. Gazder, M. Sánchez-Araiza, J.J. Jonas, E.V. Pereloma, Evolution of recrystallization texture in a 0.78 wt.\% Cr extra-low-carbon steel after warm and cold rolling, Acta Mater. 59(12) (2011) 48474865. 
[30] L. Chang, H.K.D.H. Bhadeshia, Austenite films in bainitic microstructures, Mater. Sci. Tech. Ser. 11(9) (1995) 874-882.

[31] S.S.F. Dafé, F.L. Sicupira, F.C.S. Matos, N.S. Cruz, D.R. Moreira, D.B. Santos, Effect of cooling rate on $\left(\varepsilon, \alpha^{\prime}\right)$ martensite formation in twinning/transformation-induced plasticity Fe-17Mn-0.06 C steel, Mat. Res. 16(6) (2013) 1229-1236.

[32] S. Takaki, H. Nakatsu, Y. Tokunaga, Effects of austenite grain size on epsilon martensitic transformation in Fe-15mass\%Mn alloy, Mater. Trans. 34(6) (1993) 489-495.

[33] A.A. Saleh, D.W. Brown, E.V. Pereloma, B. Clausen, C.H. Davies, C.N. Tomé, A.A. Gazder, An in-situ neutron diffraction study of a multi-phase transformation and twinning-induced plasticity steel during cyclic loading, Appl. Phys. Lett. 106(17) (2015) 171911.

[34] S. Pramanik, D.R.G. Mitchell, A.A. Saleh, A.A. Gazder, E.V. Pereloma, Evolution of microstructure during the in-situ heating of $42 \%$ cold-rolled high Mn steel, Metall. Mater. Trans. A (Under review) (2018).

[35] G. Krauss, Fine structure of austenite produced by the reverse martensitic transformation, Acta Metall. Mater. 11(6) (1963) 499-509.

[36] P. Chapellier, R.K. Ray, J.J. Jonas, Prediction of transformation textures in steels, Acta Metall. Mater. 38(8) (1990) 1475-1490.

[37] R. Ray, J.J. Jonas, M. Butrón-Guillén, J. Savoie, Transformation textures in steels, ISIJ Int. 34(12) (1994) 927-942.

[38] M.C. Somani, P. Juntunen, L.P. Karjalainen, R.D.K. Misra, A. Kyröläinen, Enhanced mechanical properties through reversion in metastable austenitic stainless steels, Metall. Trans. A 40(3) (2009) 729-744.

[39] M. Odnobokova, A. Belyakov, N. Enikeev, D.A. Molodov, R. Kaibyshev, Annealing behavior of a 304L stainless steel processed by large strain cold and warm rolling, Mater. Sci. Eng. A (2017).

[40] H.-W. Yen, S.W. Ooi, M. Eizadjou, A. Breen, C.-Y. Huang, H.K.D.H. Bhadeshia, S.P. Ringer, Role of stress-assisted martensite in the design of strong ultrafine-grained duplex steels, Acta Mater. 82 (2015) 100-114.

[41] T.W. Duerig, J. Albrecht, D. Richter, P. Fischer, Formation and reversion of stress induced martensite in Ti-10V-2Fe-3Al, Acta Metall. 30(12) (1982) 2161-2172.

[42] Y. Tomota, M. Strum, J.W. Morris, Microstructural dependence of Fe-high Mn tensile behavior, Metall. Trans. 17(3) (1986) 537-547.

[43] H. Ding, H. Ding, D. Song, Z. Tang, P. Yang, Strain hardening behavior of a TRIP/TWIP steel with 18.8\% Mn, Mater. Sci. Eng. A 528(3) (2011) 868-873. 


\section{Supplementary Section}

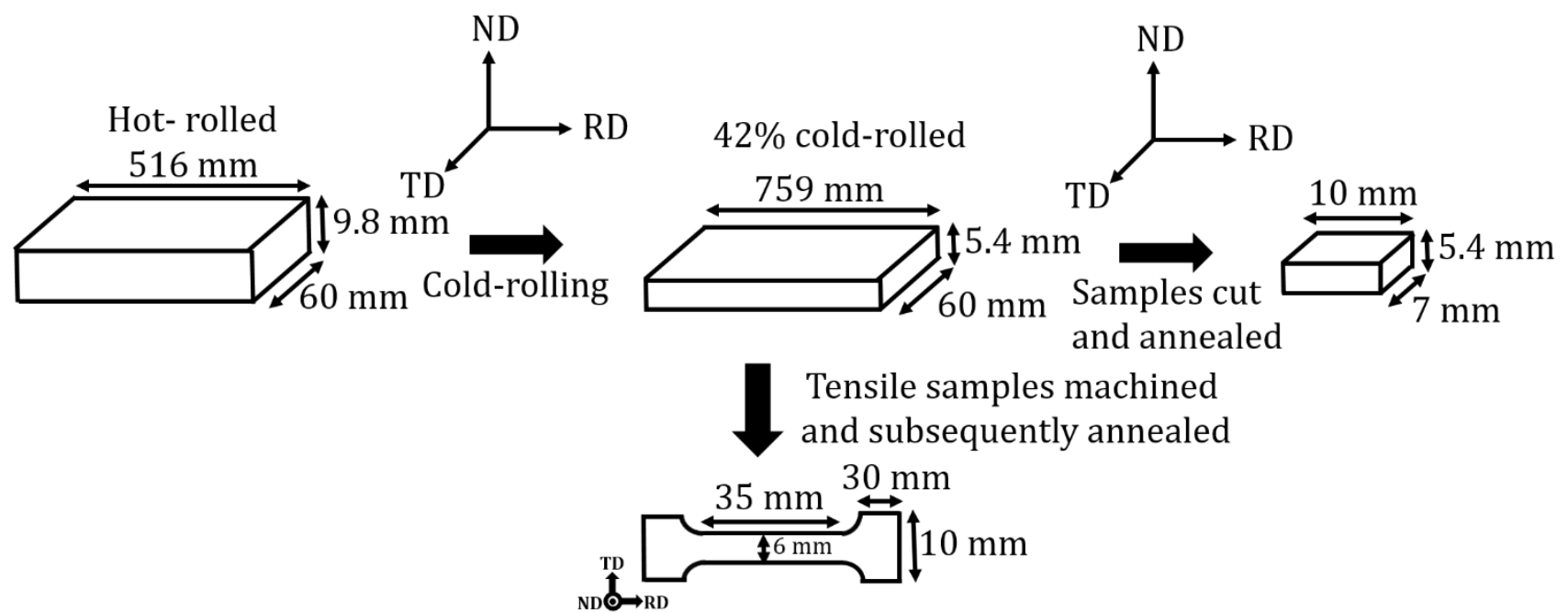

Figure S1: Schematic showing the processing of the samples.

The ODFs of the hot-rolled sample for the $\gamma, \varepsilon$ and $\alpha^{\prime}$-martensite is represented in supplementary Fig. S2. The $\gamma$ in the hot-rolled sample shows weak $\alpha_{\gamma}$-fibre $\left(\langle 110\rangle_{\gamma}|| N D\right)\{110\}\langle 223\rangle_{\gamma}\left(\phi_{1}=42^{\circ}, \Phi=90^{\circ}, \phi_{2}=45^{\circ}\right)$ orientation, along with Copper $\left(\mathrm{Cu},\{112\}\langle 111\rangle_{\gamma}\right), \mathrm{S}\left(\{123\}\langle 634\rangle_{\gamma}\right)$ and Cube $\left(\mathrm{C},\{100\}\langle 001\rangle_{\gamma}\right)$ orientations. The $\varepsilon$-martensite formed upon quenching after hot-rolling shows weak intensity along the $\{h k i l\}_{\varepsilon}$-fiber $\sim\{\overline{1} 2 \overline{1} 5\}\langle 1 \overline{2} 13\rangle_{\varepsilon}\left(\phi_{1}=90^{\circ}, \Phi=24^{\circ}, \phi_{2}=0^{\circ}\right)$ and $\sim\{01 \overline{1} 3\}\langle 0 \overline{1} 12\rangle_{\varepsilon}\left(\phi_{1}=88^{\circ}, \Phi=34^{\circ}, \phi_{2}=30^{\circ}\right)$ orientations. The $\alpha^{\prime}$-martensite formed upon quenching after hot-rolling returns $\alpha_{\alpha^{\prime}}$-fibre $\left(\langle 110\rangle_{\alpha^{\prime}}|| \mathrm{RD}\right)(001)[1 \overline{1} 0]_{\alpha^{\prime}}$ orientation and weak intensities around the $\gamma_{\alpha^{\prime}}$-fibre $\left(\langle 111\rangle_{\alpha^{\prime}}|| N D\right)$ (111) $[\overline{1} \overline{1} 2]_{\alpha^{\prime}}$ orientation. 


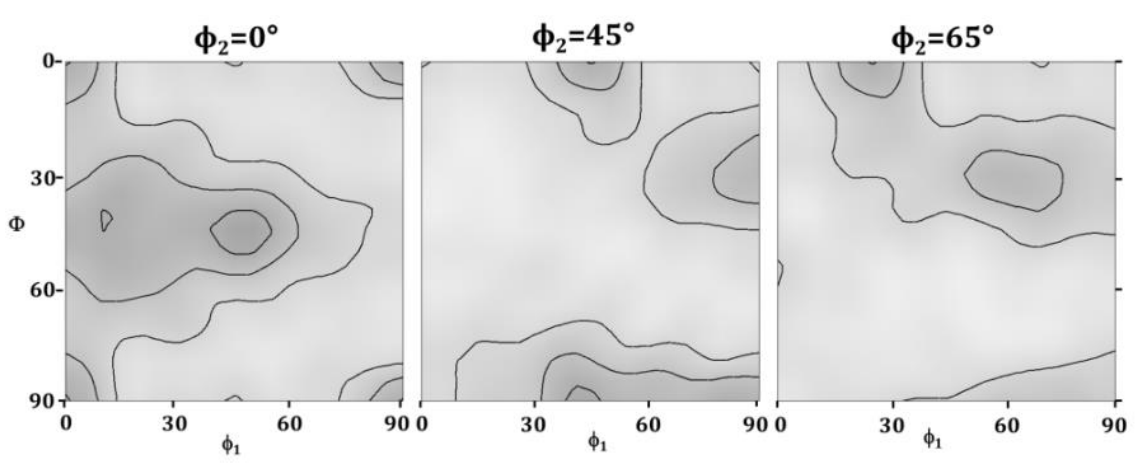

(a)

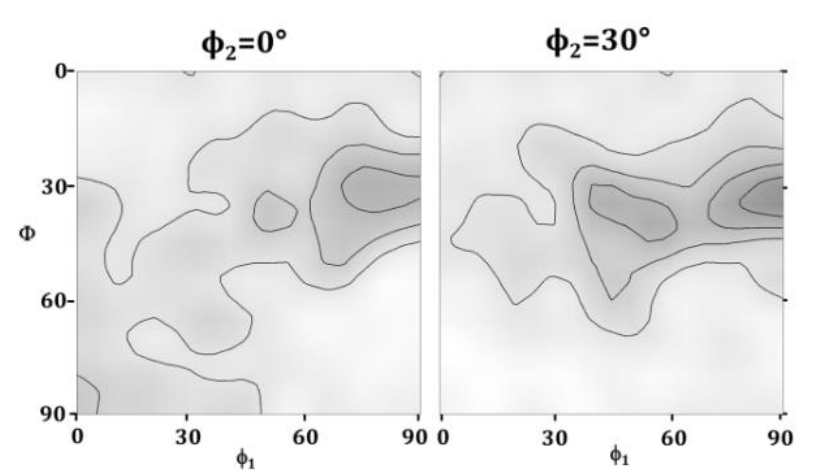

(b)

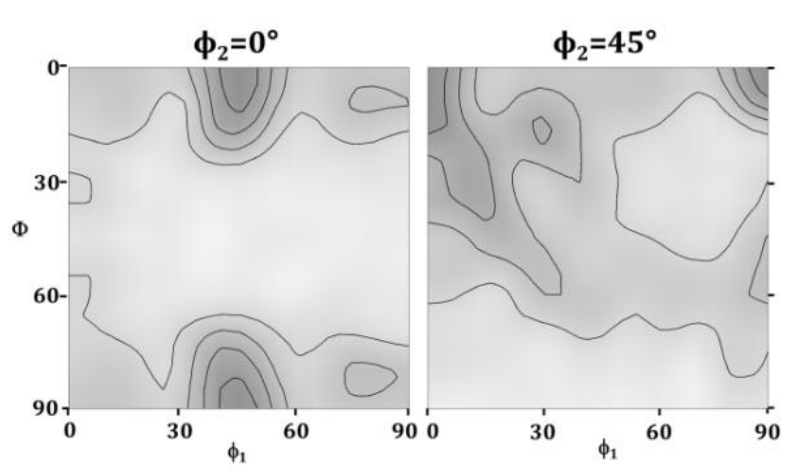

(c)

Figure S2: Orientation distribution function sections corresponding to sections (a) $\phi_{2}=0^{\circ}, 45^{\circ}$ and $65^{\circ}$ of $\gamma$, (b) $\phi_{2}=0^{\circ}, 30^{\circ}$ of $\varepsilon$-martensite and (c) $\phi_{2}=0^{\circ}, 45^{\circ}$ of $\alpha^{\prime}$-martensite for the hot-rolled sample. 


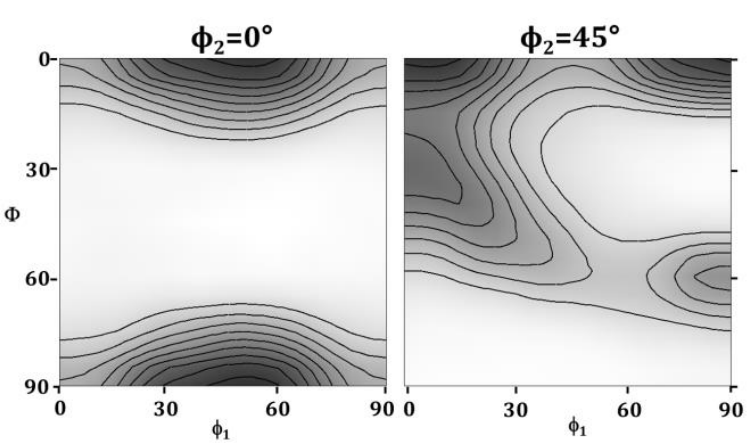

(a)

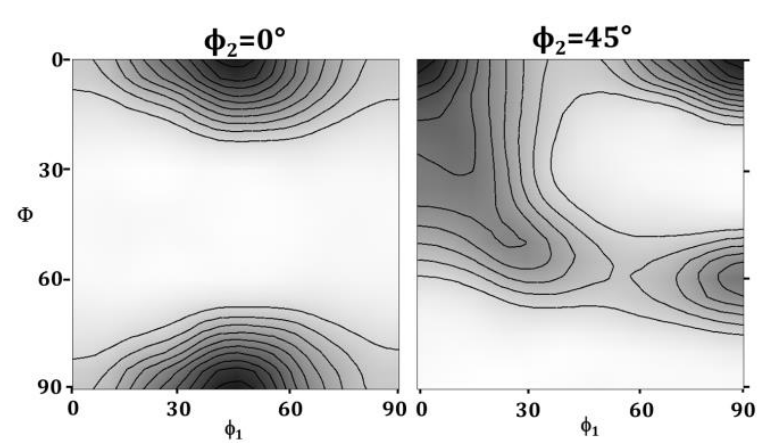

(b)

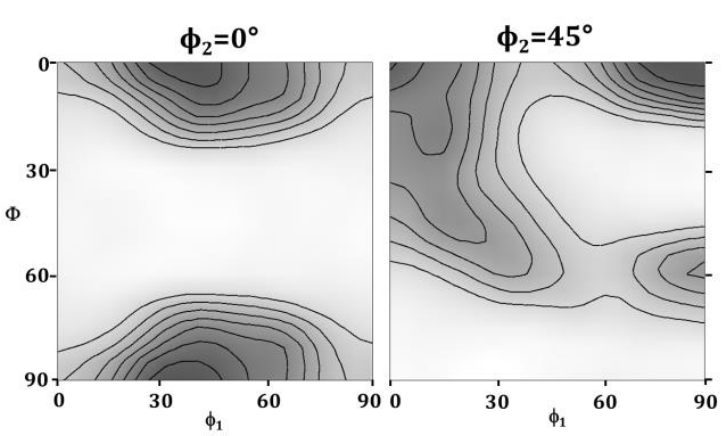

(c)

Figure S3: $\phi_{2}=0^{\circ}$ and $45^{\circ}$ orientation distribution function sections of $\alpha^{\prime}$-martensite after annealing at (a) $500{ }^{\circ} \mathrm{C}$, (b) $600{ }^{\circ} \mathrm{C}$ and (c) $625{ }^{\circ} \mathrm{C}$. Contour levels $=0.5 \times$

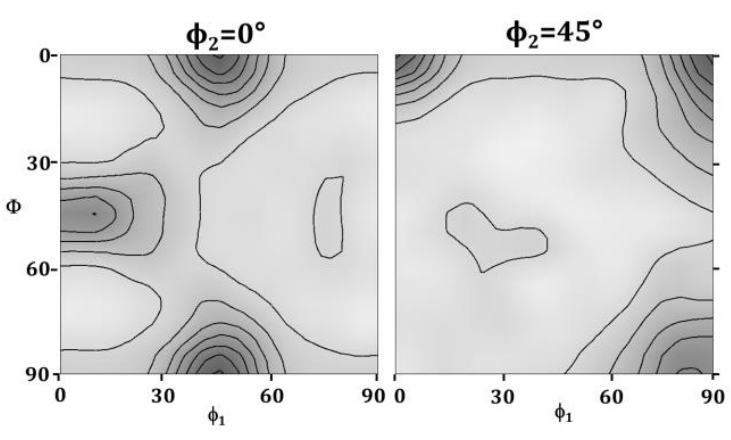

(a)

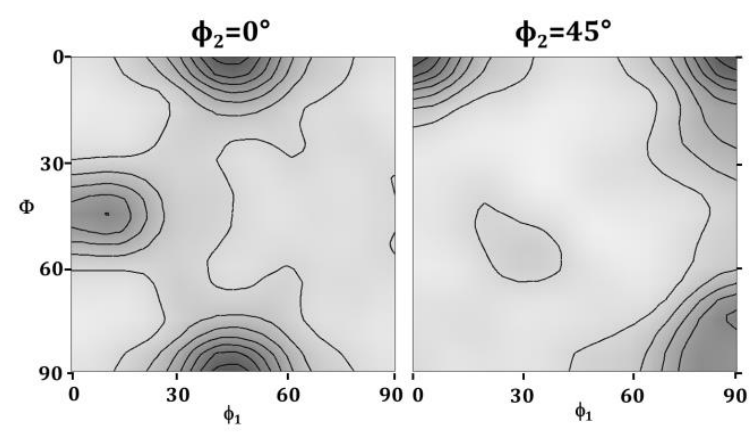

(b)

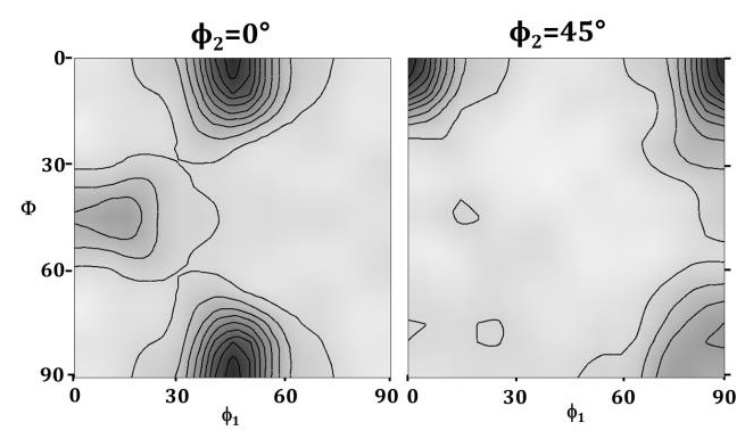

(c)

Figure S4: $\phi_{2}=0^{\circ}$ and $45^{\circ}$ orientation distribution function sections of $\alpha^{\prime}$-martensite after annealing at (a) $700{ }^{\circ} \mathrm{C}$, (b) $750{ }^{\circ} \mathrm{C}$ and (c) $800{ }^{\circ} \mathrm{C}$. Contour levels $=0.5 \times$ 


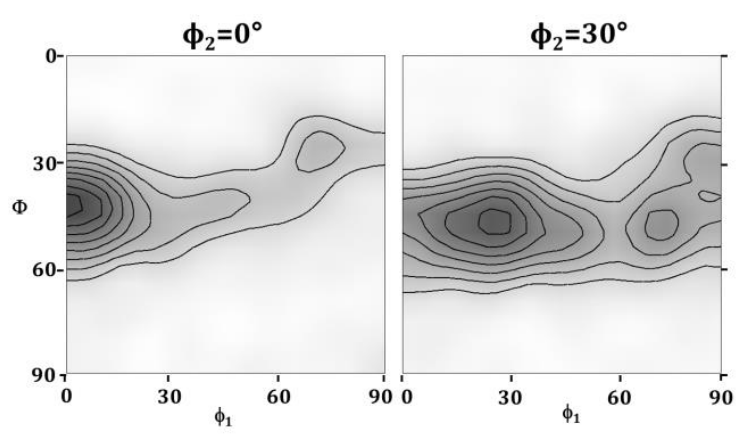

(a)

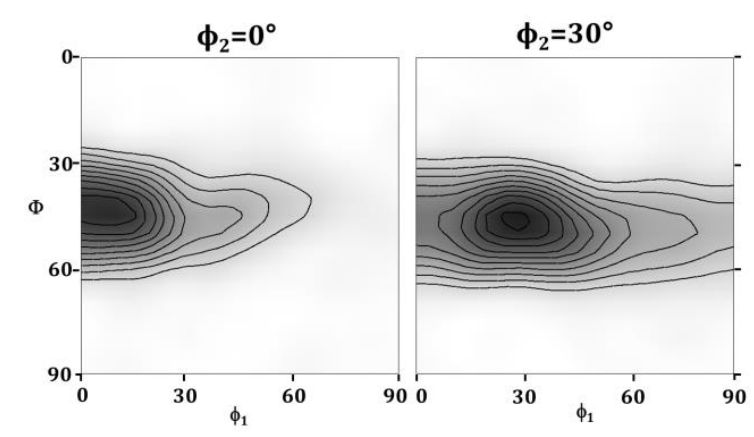

(b)

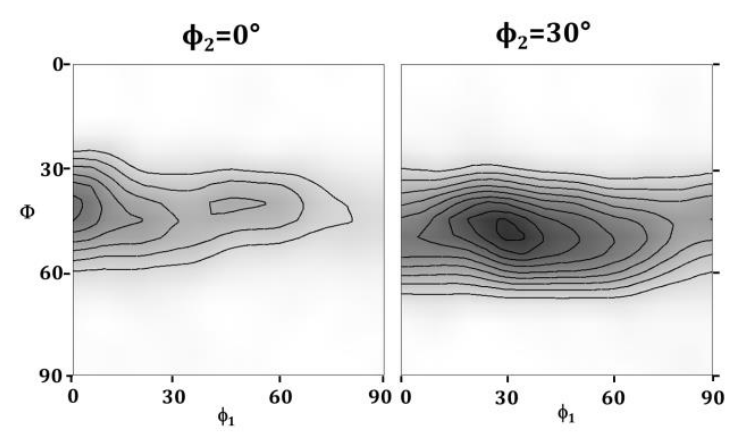

(c)

Figure S5: $\phi_{2}=0^{\circ}$ and $30^{\circ}$ orientation distribution function sections of $\varepsilon$-martensite after annealing at (a) $700{ }^{\circ} \mathrm{C}$, (b) $750{ }^{\circ} \mathrm{C}$ and (c) $800{ }^{\circ} \mathrm{C}$. Contour levels $=0.5 \times$

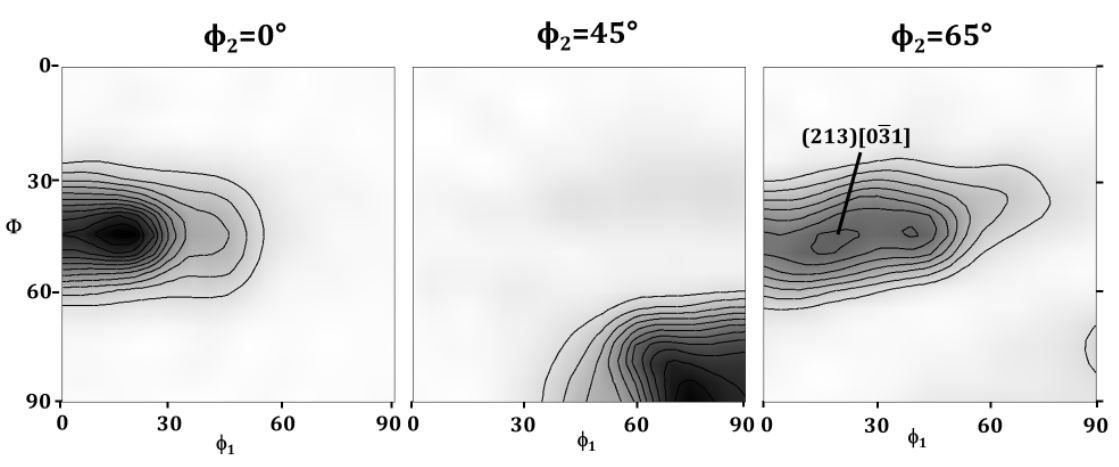

(a)

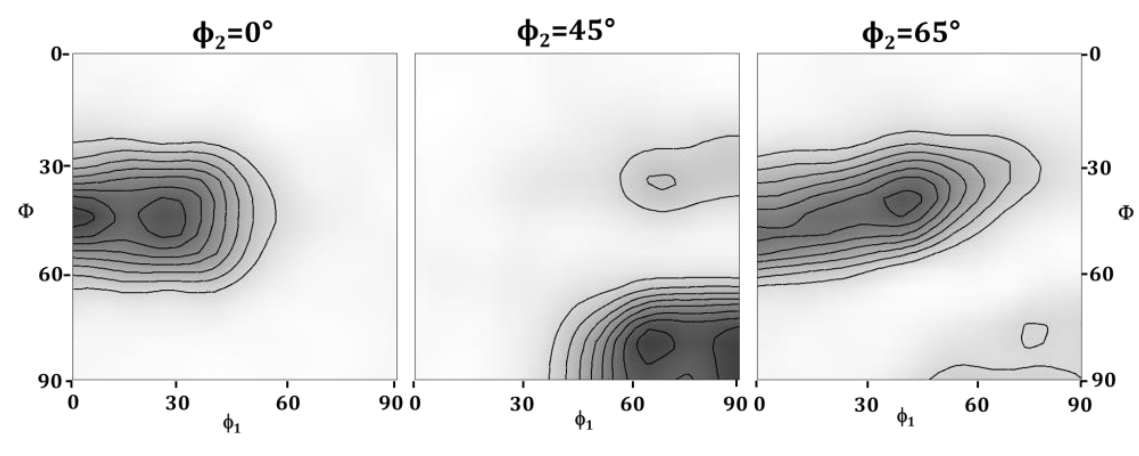

(b) 


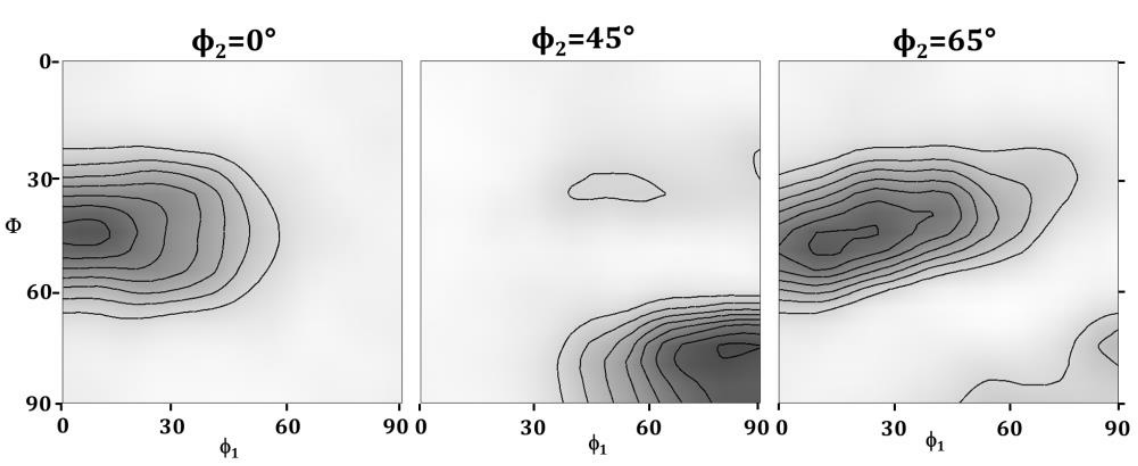

(c)

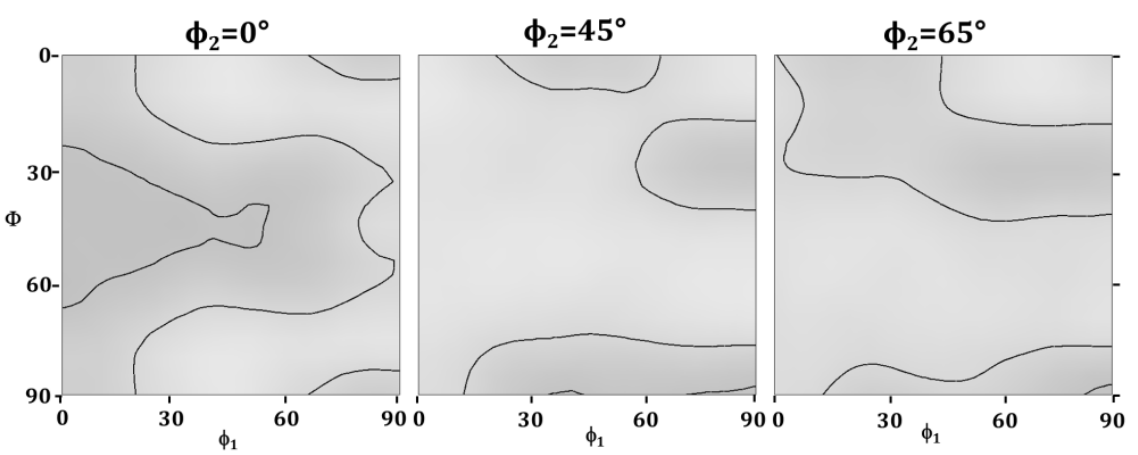

(e)
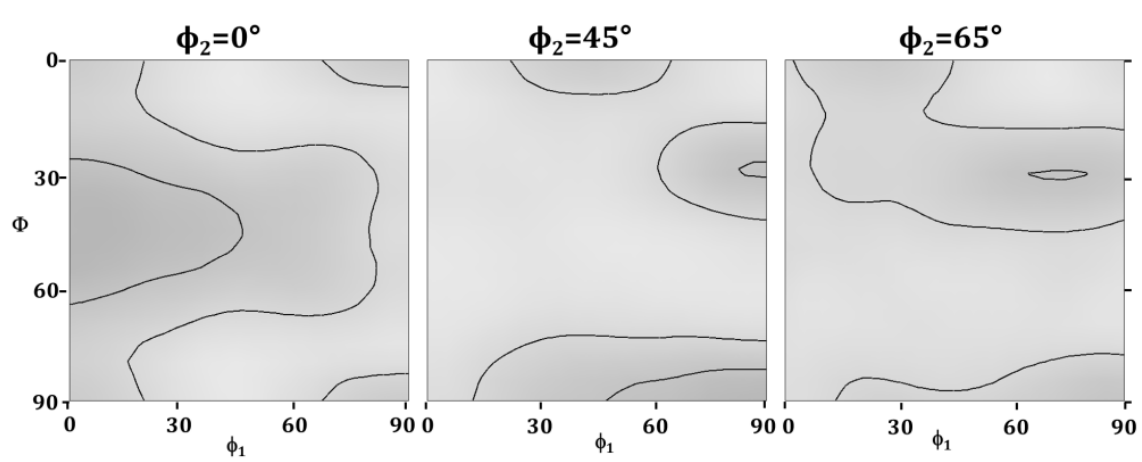

(d)
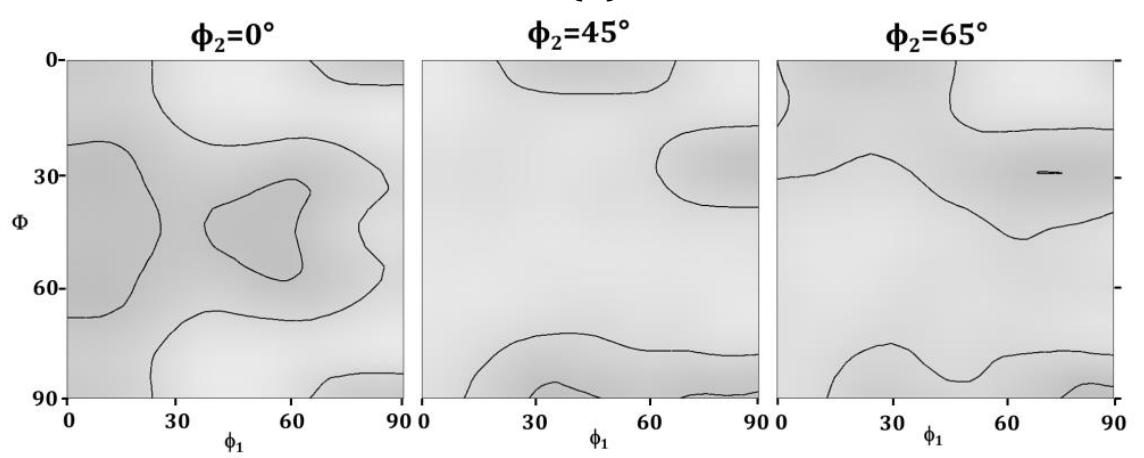

(f)

Figure S6: $\phi_{2}=0^{\circ}, 45^{\circ}$ and $65^{\circ}$ orientation distribution function sections of $\gamma$ after annealing at (a) $500{ }^{\circ} \mathrm{C}$, (b) $600{ }^{\circ} \mathrm{C},(\mathrm{c}) 625^{\circ} \mathrm{C}$, (d) $700{ }^{\circ} \mathrm{C}$, $(\mathrm{e}) 750$ ${ }^{\circ} \mathrm{C}$ and (f) $800{ }^{\circ} \mathrm{C}$. Contour levels $=0.5 \times$ 


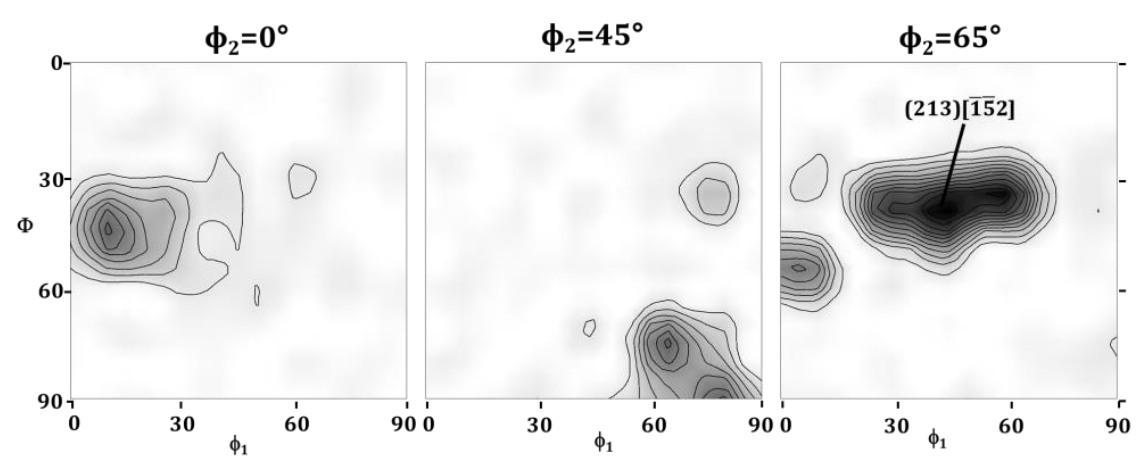

(a)

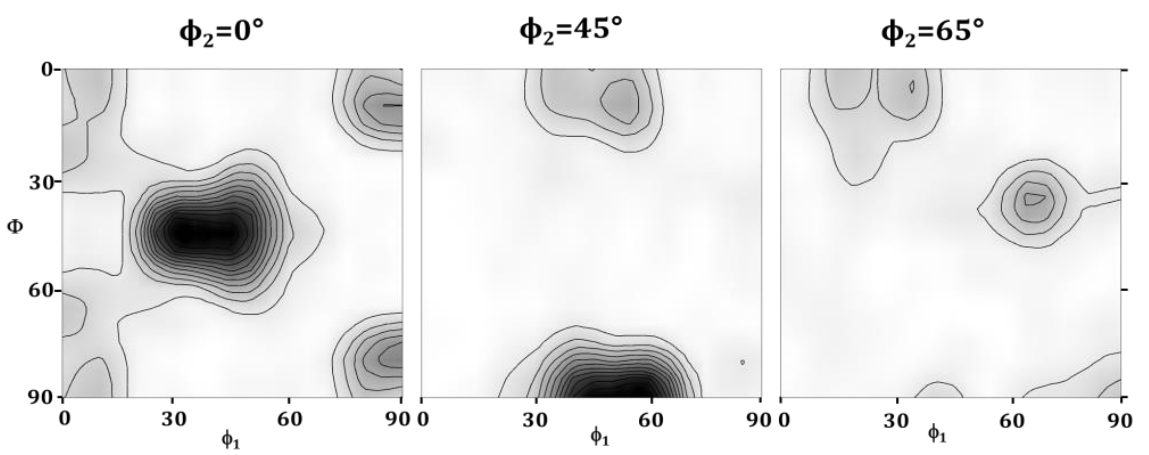

(c)

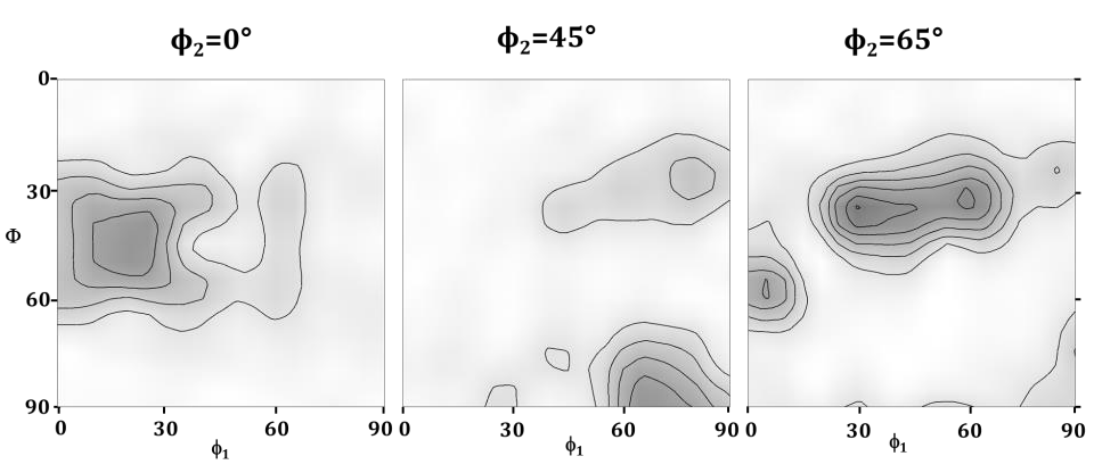

(b)

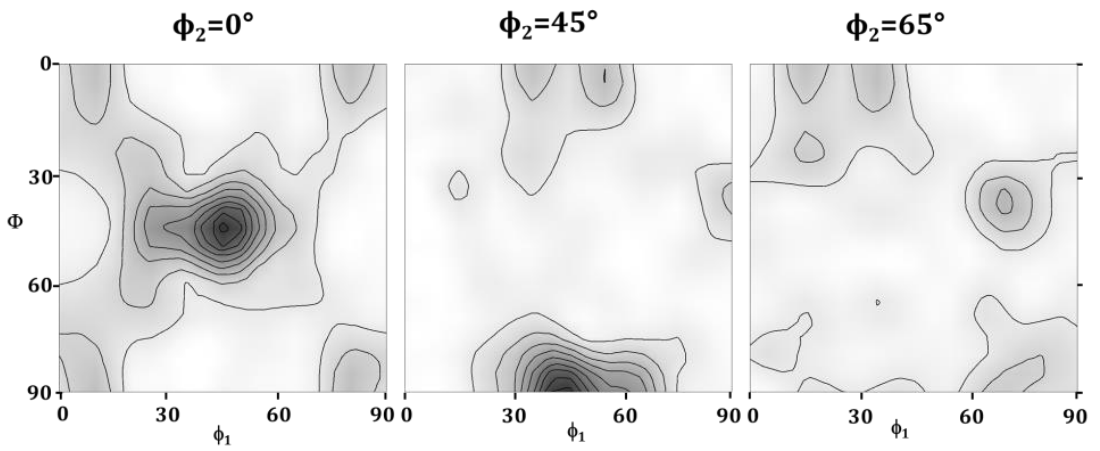

(d)

Figure S7: $\phi_{2}=0^{\circ}, 45^{\circ}$ and $65^{\circ}$ orientation distribution function sections of $\gamma$ grains segmented into (a, c) reverted/recovered and (b, d) recrystallised fractions after annealing at $(\mathrm{a}, \mathrm{b}) 600^{\circ} \mathrm{C}$ and $(\mathrm{c}, \mathrm{d}) 650^{\circ} \mathrm{C}$. Contour levels $=0.5 \times$ 


\section{Graphical abstract}

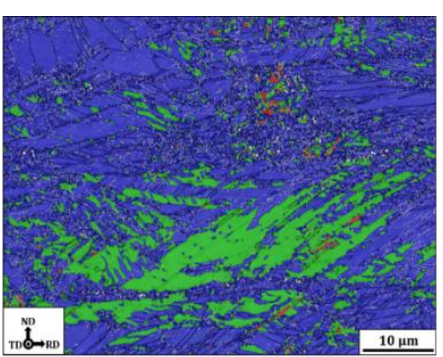

Cold-rolled

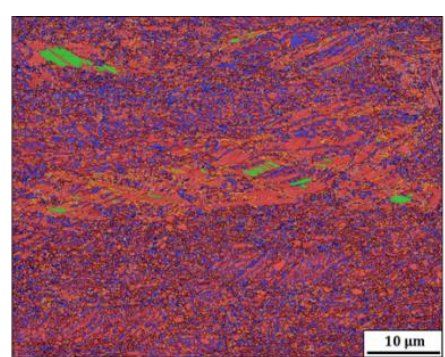

Partially

Reverted/Recrystallised $\left(625^{\circ} \mathrm{C}\right)$

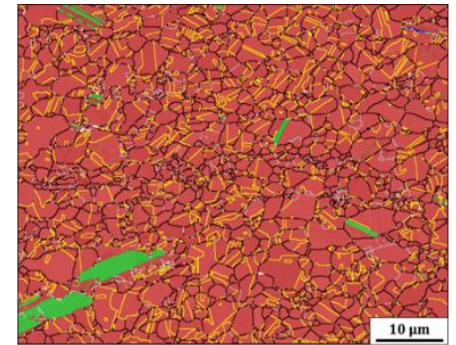

Fully Recrystallised $\left(700^{\circ} \mathrm{C}\right)$

Red: $\gamma$, Green: $\varepsilon$-martensite, Blue: $\alpha^{\prime}$-martensite

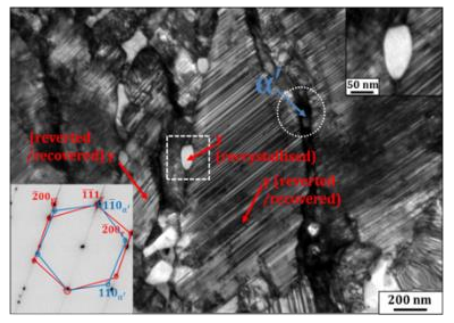

TEM and Segmented EBSD Microstructures 


\section{Highlights}

- Recrystallised $\gamma$ grains have similar orientations to reverted/recovered $\gamma$ grains.

- After reversion, $\gamma$ orientations are correlated to $\varepsilon$ and $\alpha^{\prime}$-martensite orientations.

- $\gamma$ nucleation at the boundary of reverted/recovered $\gamma$ grains. 